\title{
Impact of Nudging Parameters on Dynamical Downscaling over CORDEX East Asia Phase II Domain: The Case of Summer 2003 2
}

\author{
Linyun YAng, Shuyu Wang, Jianping Tang, Xiaorui NiU, and Congbin Fu \\ School of Atmospheric Sciences, and CMA-NJU Joint Laboratory for Climate Prediction Studies, Institute for \\ Climate and Global Change Research, Nanjing University, Nanjing, China
}

(Manuscript received 14 June 2019, in final form 28 September 2019)

\begin{abstract}
In this paper, the sensitivity of the Weather Research and Forecasting (WRF) Model to the nudging parameters in simulating July-August (JJA) precipitation was assessed with 16 experiments over the Coordinated Regional Climate Downscaling Experiment East Asia II (CORDEX-EA-II) domain. The effects of various nudging parameters in spectral nudging (referred to as $\mathrm{SN}$ ) and grid nudging (referred to as AN) experiments are examined, including wavenumbers, relaxation time, nudging levels, and nudging variables for SN and relaxation time and nudging variables for AN. Results showed that the applications of spectral nudging and grid nudging methods in WRF simulations can improve the model's ability to reproduce the JJA extreme precipitation event and accompanying large-scale fields in 2003. The major findings include 1) spectral nudging is superior to grid nudging in simulating heavy rainfall and low-level circulation, 2) nudging both kinematic and thermodynamic variables is efficient to better simulate the JJA precipitation for both SN and AN simulations, 3) in SN simulations, the options of wavenumbers display stronger impact on JJA precipitation if nudging solely the kinematic variables instead of both kinematic and thermodynamic variables over wet subregions, and 4) the free developed large-scale processes associated with small nudging wavenumbers can diminish the improvement from nudging both kinematic and thermodynamic variables in simulating subseasonal variations of precipitation. Overall, the experiment that adopts spectral nudging of both kinematic and thermodynamic variables, 1-h relaxation time, and four or eight nudging wavenumbers captures the characteristics of summer climate more reasonably.
\end{abstract}

\section{Introduction}

Interpreting climate change at the local scale accurately is significant for society and governments to take action against the inevitable changes. Global climate models (GCMs) have been widely used in climate change at global and continental levels (Klutse et al. 2016; Kulkarni et al. 2016), but with improving resolution they still have difficulties to meet the requirements of regional mitigation and adaptation to climate change (Leung et al. 2003; Tiwari et al. 2014; Boberg et al. 2010; Fowler et al. 2007). To produce accurate climate change information at the regional scale, dynamical downscaling methods using regional climate models (RCMs) are widely applied with their higher resolution and better

Supplemental information related to this paper is available at the Journals Online website: https://doi.org/10.1175/JAMC-D-190152.s1.

Corresponding author: Shuyu Wang,wsy@nju.edu.cn representations of the regional forcings, such as local topography and mesoscale features (Leung et al. 2003; Feser et al. 2011; Rockel 2015; Giorgi 2006; Domínguez et al. 2013). Over East Asia, RCMs have been used to study the regional climatology, climate extremes, monsoon variability, and climate change projections (Niu et al. 2018; Cha et al. 2008; Hui et al. 2015; Zhao 2013; Gao and Giorgi 2017).

The performance of RCMs is influenced by many factors. In addition to the limitation in models' physical processes, RCMs are influenced by the large-scale forcing provided by GCMs or observations at the lateral boundaries. Their inner-domain performance could be modulated, as RCM-generated large-scale fields are constrained to be consistent with the enforced inflows and outflows at the boundaries (Leung et al. 2003). When integrating over a large domain, the model biases could accumulate continuously in the inner domain and lead to the deviation of RCMs' large-scale circulation from observations. To ensure the dynamic consistency between the simulated large-scale variables and the 
driving fields, the interior nudging technique, including grid nudging (Bowden et al. 2012) and spectral nudging (von Storch et al. 2000; Tang et al. 2010; Cha and Lee 2009), has been increasingly used in regional climate simulations (Liu et al. 2012; Vincent and Hahmann 2015). Grid nudging is a scale-indiscriminate interior constraint technique and uses Newtonian relaxation to adjust the model predictions at individual grid points. Meanwhile, spectral nudging uses a scale-selective interior constraint to nudge the waves with lengths longer than the selected scale in spectral space. Spectral nudging in RCM simulations is usually applied to the upper atmosphere and increases with height, which keeps the dynamics of RCMs creating small-scale to mesoscale features at the lower atmosphere and at the same time ensures the consistency of RCM with driving data at the upper atmosphere (Hong and Chang 2012; Heikkilä et al. 2011; Radu et al. 2008).

Studies show that both the grid and spectral nudging can effectively improve the performance of RCMs by displaying better consistency with large-scale circulation patterns (Spero et al. 2014; Vincent and Hahmann 2015). Lucas-Picher et al. (2016) investigated the contribution of large-scale nudging to the improvement in regional climate simulations and found that the largescale nudging was necessary to reproduce daily weather regimes and seasonal anomalies. Liu et al. (2012), however, found that spectral nudging provided better simulation at the large and small scales with the proper choice of wavenumbers, when comparing the downscaled results from spectral and grid nudging.

For both the grid and spectral nudgings, the nudging parameters include the variables relaxation time and levels. And for the spectral nudging, the wavenumbers must be considered. Nudging variables clearly affect the skill scores of RCM (Omrani et al. 2015), and the horizontal winds are the key in all variables to correctly simulate the surface variables and circulation (Kuo et al. 1993). Nudging moisture may further improve the representation of mean and extreme precipitation (Spero et al. 2014). The nudging relaxation time controls the nudging strength, that is, the shorter the relaxation time, the closer the model simulated variables to the driving fields (Salameh et al. 2010; Omrani et al. 2013). In spectral nudging simulations, the RCM performance is sensitive to the selection of wavelength (Gómez and Miguez-Macho 2017; Tang et al. 2017), as nudging smaller wavelength damps the finescale contribution of RCM. The vertical profile of nudging also plays a vital role in generating realistic regional structures (von Storch et al. 2000). In Asia, various studies have been carried out to investigate the improvement from spectral nudging in RCMs in simulating the East Asian monsoon, tropical typhoons, and precipitation (Yhang and Hong 2011; Feser and Barcikowska 2012; Shan et al. 2012; Cha and Lee 2009; Ramzan et al. 2017; Cha et al. 2011). However, these studies seldom analyzed the differences between nudging parameters but usually focused on nudging schemes or methods.

Over the large domain of World Climate Research Programme-Coordinated Regional Climate Downscaling Experiment East Asia (WCRP-CORDEX-EA, Giorgi et al. 2009; Lake et al. 2017), many studies have been devoted to evaluating the RCMs' performance (Park et al. 2013; Zhou et al. 2016; Tang et al. 2017; Jin et al. 2016; Hong and Chang 2012; Huang et al. 2015) and to projecting the regional climate change (Lee and Moon 2014; Zou and Zhou 2016; Oh et al. 2014). Sensitivity studies aiming to examine model physics and the effect of spectral nudging were carried out over the CORDEX East Asia domain as well. However, research on the effects of different nudging techniques and options of nudging parameters was limited (Tang et al. 2017; Hong and Chang 2012).

In this study, we explore the effects of different interior nudgings and the influences of nudging parameters on regional climate simulation over the CORDEXEA-II domain for the summer of 2003. During the time period of interest, the regional climate was characterized by both temperature and precipitation extremes, including hot weather in the regions south of the Yangtze River and floods in the Huaihe River basin. Our objectives are 1) to investigate the sensitivity of precipitation to different nudging choices and 2) to identify a suitable combination of nudging parameters for climate simulation over the CORDEX East Asia phase II domain. This paper is organized as follows: section 2 briefly introduces the interior nudging methods, section 3 describes data and model experiments, and section 4 shows the simulation results and the effect of interior nudging on regional climate simulation. In the final section, the discussion and conclusions are given.

\section{Interior nudging techniques}

With the application of interior nudging, the model simulation is relaxed toward the reference value not only at the lateral boundary but also in the internal domain. In two different nudging methods, grid nudging first defines an artificial tendency term, which can be calculated as the difference between the observation and model solution weighted by the nudging coefficients. The model state is then relaxed toward the driving large-scale fields using the above tendency term at each model grid (Stauffer and Seaman 1994). The nudging equation is expressed by 


$$
\partial \alpha / \partial t=F(\alpha, x, t)+G_{\alpha} W(x, t) V(z)\left(\hat{\alpha}_{0}-\alpha\right),
$$

where $\alpha(x, t)$ is the model variable, $F(\alpha, x, t)$ is the time tendency of model's fields, and $\hat{\alpha}_{0}$ denotes the analysis or observation that is interpolated to the model grid. The method has three nudging parameters: 1) $G_{\alpha}$, the nudging strength and also known as the relaxation coefficient, which is inversely proportional to the $e$-folding time; 2) $W(x, t)$, the time-dependent weight, which is used to nudge the observation at the specified time step; and 3) $V(z)$, the vertical weight factor, which ranges from 0 to 1 and is applied to remove the impact of surface.

Spectral nudging has a similar strategy to that of grid nudging, only spectral nudging applies the relaxation toward the selected wavelengths. Spectral nudging is expressed as

$$
\partial \alpha / \partial t=F(\alpha, x, t)+G_{\alpha} W(x, t) V(z) \times \text { Filter }_{x y}\left[\left(\hat{\alpha}_{0}-\alpha\right)\right],
$$

where Filter $x y$ is the spectral filtering, which is used to control the wavenumber. The spatial waves shorter than the selected cutoff wavelength can be preserved and the longer waves from large-scale forcing are nudged.

\section{Model and experimental designs}

\section{a. Model description and configuration}

The regional climate model used in this work was the Weather Research and ForecastingModel, version 3.6.1 (WRF V3.6.1) (Skamarock et al. 2008). Following the CORDEX-EA phase II framework, the model domain was centered at $\left(35^{\circ} \mathrm{N}, 116^{\circ} \mathrm{E}\right)$, with $385 \times 253$ grid points in the west-east and north-south directions (Fig. 1). The simulation had a horizontal resolution of $25 \mathrm{~km}$ and 30 sigma levels in the vertical direction with a model top at $50 \mathrm{hPa}$. The model domain covered East Asia and part of South and Southeast Asia. Six subregions were used for results analysis (Fig. 1): East Asia $\left(\mathrm{EA} ; 12^{\circ}-55^{\circ} \mathrm{N}, 72^{\circ}-150^{\circ} \mathrm{E}\right.$ ), South China (SC; $18^{\circ}-26^{\circ} \mathrm{N}$, $107^{\circ}-123^{\circ} \mathrm{E}$ ), the Yangtze River basin (YRB; $26^{\circ}-34^{\circ} \mathrm{N}$, $\left.107^{\circ}-123^{\circ} \mathrm{E}\right)$, North China $\left(\mathrm{NC} ; 34^{\circ}-42^{\circ} \mathrm{N}, 107^{\circ}-123^{\circ} \mathrm{E}\right)$, Northeast China $\left(\mathrm{NEC} ; 42^{\circ}-53^{\circ} \mathrm{N}, 114^{\circ}-134^{\circ} \mathrm{E}\right)$, and Northwest China (NWC; $36^{\circ}-48^{\circ} \mathrm{N}, 77^{\circ}-100^{\circ} \mathrm{E}$ ).

All of the WRF experiments used identical physical parameterizations. The physical options consisted of the WRF single-moment 5-class scheme for microphysics (WSM5) (Lim and Hong 2010), the convective parameterization scheme of Kain and Fritsch (1990), the Yonsei University planetary boundary layer scheme (YSU PBL) (Hong et al. 2006), and the Noah land surface model (Chen and Dudhia 2001). The longwave and shortwave radiation schemes from the Community

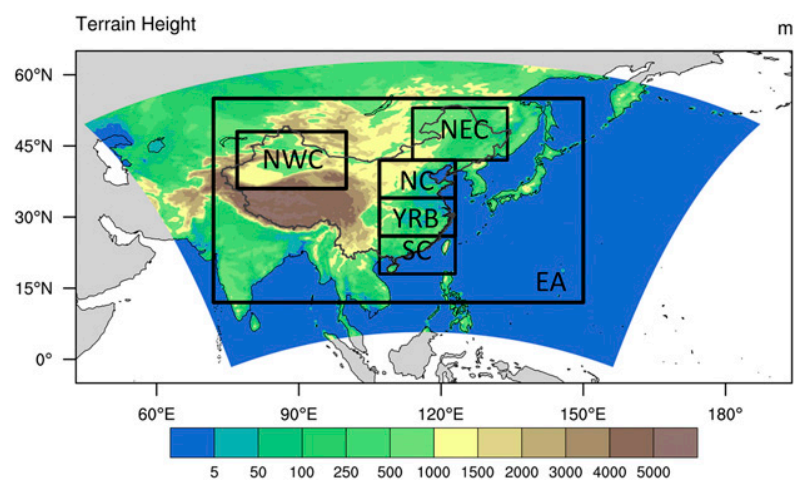

FIG. 1. WRF simulation domain (colored area). The CORDEXEA-II domain is divided into six subregions as labeled: EA, NEC, NC, YRB, SC, and NWC.

Atmosphere Model (CAM) (Collins et al. 2004) are used for the terrestrial and solar radiation processes.

The initial and boundary conditions and sea surface temperatures (SSTs) were from the ERA-Interim reanalysis data (ECMWF 2009; Dee et al. 2011), which has a resolution of $0.75^{\circ} \times 0.75^{\circ}$. The model was initialized at 0000 UTC 16 May 2003 and integrated continuously for 106 days. With the first 15 days as the spinup period, the whole summer of 2003 is used for analysis.

\section{b. Experimental designs}

To investigate the impacts of interior nudging methods and their parameters on regional climate simulation over CORDEX-EA II domain, 16 WRF experiments were performed. With CTL referring to as the control run (Table 1), the rest of the experiments were divided into five groups. The UV group contained three WRF experiments (SN8UV, SN4UV, and SN2UV), which spectrally nudged the horizontal wind with first wavenumbers of 8,4 , and 2 above the planetary boundary layer every hour. In the ALL group, the variables of horizontal wind, potential temperature, and geopotential height were nudged with wavenumbers of 8,4 , and 2 every hour. With the large domain size of CORDEX-EA being around $4700 \mathrm{~km} \times 3100 \mathrm{~km}$, the nudging wavenumbers of 8,4 , and 2 corresponded to wavelengths of about 500,1000, and $2000 \mathrm{~km}$, respectively. The RELAX group had the same nudging parameters as those in ALL group, except for the relaxation time that was set to be $3 \mathrm{~h}$ to represent a lower nudging coefficient of $1 \times 10^{-4} \mathrm{~s}^{-1}$ and consequently a weaker nudging strength. Similarly, the grid nudging experiments include the UV, ALL, and RELAX groups, but for the ANALL and ANALL3h (the ALL and RELAX groups for AN) experiments, the nudging variables consisted of water vapor mixing ratio as well as horizontal wind, potential temperature. An extra group 
TABLE 1. Ensemble experimental design, options for nudging type, wavenumbers, nudging variables, relaxation time, and nudging levels. Here, $u, v, t, q$, and $h$ represent the $U$ and $V$ wind components, potential temperature, water vapor mixing ratio, and geopotential height. When $\mathrm{dk}$ is set to 10 , if the planetary boundary layer is lower than model level 10 then nudging will start from the planetary boundary layer, the nudging strength will increase linearly, and it will reach full strength at model level 10; otherwise, the starting nudging level will be set to model level 10 and the variables will be nudged with full nudging strength above model level 10 . When $\mathrm{dk}$ is set to $15 \mathrm{dor}$ 20 , the nudging will start from the planetary boundary layer and the nudging strength will increase linearly to full strength at model level 15 or 20 , respectively, and then the nudging strength will remain stable.

\begin{tabular}{|c|c|c|c|c|c|c|c|}
\hline \multirow[b]{2}{*}{$\begin{array}{l}\text { Expt } \\
\text { group }\end{array}$} & \multirow[b]{2}{*}{$\begin{array}{l}\text { Expt no. and } \\
\text { name }\end{array}$} & \multirow[b]{2}{*}{$\begin{array}{l}\text { Nudging } \\
\text { type }\end{array}$} & \multicolumn{2}{|c|}{ Wavenumbers } & \multirow[b]{2}{*}{$\begin{array}{l}\text { Nudging } \\
\text { variables }\end{array}$} & \multirow[b]{2}{*}{$\begin{array}{l}\text { Relax } \\
\text { time }\end{array}$} & \multirow[b]{2}{*}{$\begin{array}{l}\text { Levels } \\
\mathrm{dk}\end{array}$} \\
\hline & & & $X$ & $Y$ & & & \\
\hline CTL & $1 \mathrm{CTL}$ & None & - & - & - & - & - \\
\hline \multirow{3}{*}{ UV } & 2 SN8UV & SN & 8 & 8 & $u, v$ & $1 \mathrm{~h}$ & - \\
\hline & 3 SN4UV & SN & 4 & 4 & $u, v$ & $1 \mathrm{~h}$ & - \\
\hline & 4 SN2UV & SN & 2 & 2 & $u, v$ & $1 \mathrm{~h}$ & - \\
\hline \multirow[t]{3}{*}{ ALL } & 5 SN8ALL & SN & 8 & 8 & $u, v, t, h$ & $1 \mathrm{~h}$ & - \\
\hline & $6 \mathrm{SN} 4 \mathrm{ALL}$ & SN & 4 & 4 & $u, v, t, h$ & $1 \mathrm{~h}$ & - \\
\hline & $7 \mathrm{SN} 2 \mathrm{ALL}$ & SN & 2 & 2 & $u, v, t, h$ & $1 \mathrm{~h}$ & - \\
\hline \multirow[t]{3}{*}{ RELAX } & 8 SN8ALL3h & SN & 8 & 8 & $u, v, t, h$ & $3 \mathrm{~h}$ & - \\
\hline & 9 SN4ALL3h & SN & 4 & 4 & $u, v, t, h$ & $3 \mathrm{~h}$ & - \\
\hline & 10 SN2ALL3h & $\mathrm{SN}$ & 2 & 2 & $u, v, t, h$ & $3 \mathrm{~h}$ & - \\
\hline \multirow[t]{3}{*}{ AN } & 11 ANUV & AN & - & - & $u, v$ & $1 \mathrm{~h}$ & - \\
\hline & 12 ANALL & AN & - & - & $u, v, t, q$ & $1 \mathrm{~h}$ & - \\
\hline & 13 ANALL3h & AN & - & - & $u, v, t, q$ & $3 \mathrm{~h}$ & - \\
\hline \multirow[t]{3}{*}{ LEVEL } & 14 SNdk10 & SN & 4 & 4 & $u, v, t, h$ & $1 \mathrm{~h}$ & 10 \\
\hline & 15 SNdk15 & SN & 4 & 4 & $u, v, t, h$ & $1 \mathrm{~h}$ & 15 \\
\hline & $16 \mathrm{SNdk} 20$ & SN & 4 & 4 & $u, v, t, h$ & $1 \mathrm{~h}$ & 20 \\
\hline
\end{tabular}

of LEVEL was included in spectral nudging experiments to examine the effect of vertical weight factor, and three vertical weight profiles were used. Previous studies have suggested that the nudging methods should be shut off in the planetary boundary layer to leave the model free to simulate mesoscale features near the ground (Hong and Chang 2012; Heikkilä et al. 2011; Radu et al. 2008). Thus, the interior nudgings were applied above the planetary boundary layer in all experiments.

For validation, the satellite-based precipitation from the Climate Prediction Center Morphing Technique (CMORPH; NOAA 2011; Joyce et al. 2004) and the large-scale reanalysis from the 55-yr Japanese Reanalysis Project (JRA-55; JMA 2013) were used as the observed datasets. CMORPH represents 3-hourly precipitation at $0.25^{\circ}$ resolution and has been widely used in RCM evaluation (Hanrahan et al. 2015; dos Santos et al. 2014). Here, the daily data of JRA-55 with a horizontal resolution of $1.25^{\circ}$ and 27 vertical levels was chosen for assessment of circulation and moisture condition because of its high quality in representing East Asian climate (Ebita et al. 2011; Chen et al. 2014).

\section{Results}

\section{a. Spatial variability of precipitation}

We compared the spatial pattern and daily precipitation intensity for precipitation among the 16 experiments to evaluate the effect from different nudging parameters on the mean climate in summer 2003 over CORDEX-EA-II domain. To express the result explicitly, we first investigated the impact of the two nudging methods, then the impacts of nudging variables and relaxation time for $\mathrm{SN}$ and $\mathrm{AN}$ experiments, and finally the impacts of nudging wavenumbers and nudging levels for SN experiments.

\section{1) The IMPACT OF NUdGING METHOdS}

In general, all nudging experiments showed an advantage over the CTL experiment for the simulation of the averaged JJA precipitation pattern east of $105^{\circ} \mathrm{E}$. In Fig. 2, the main rainfall belt of observation in summer 2003 showed a northward shift relative to a normal summer (Zhang et al. 2011), with the center of intensity of rainfall of $\sim 10 \mathrm{~mm} \cdot \mathrm{day}^{-1}$ extending from $32^{\circ}$ to $37^{\circ} \mathrm{N}$ (Fig. 2a). As shown in Fig. 2b, the CTL run overestimated the precipitation intensity over south, southeast, southwest, and central China by up to $6 \mathrm{~mm} \cdot \mathrm{day}^{-1}$, and underestimated the rainfall slightly over northern China and over western China. Application of nudging methods could reduce the absolute bias by $3.5 \mathrm{~mm} \cdot \mathrm{day}^{-1}$ for JJA precipitation over the region east of $105^{\circ} \mathrm{E}$ in China; therefore, both underestimation and overestimation of rainfall were corrected in the monsoon-related region (Figs. 2c-g). Comparing to the $\mathrm{SN}$ experiments, $\mathrm{AN}$ groups produced 


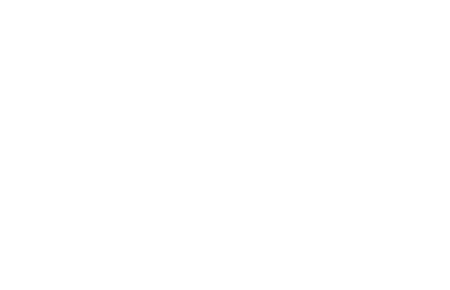

(b) $\mathrm{CTL}$

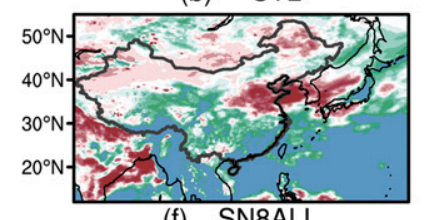

(f) SN8ALL

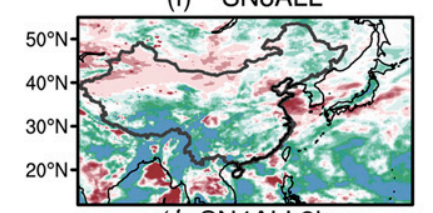

(1) SN4ALL3h

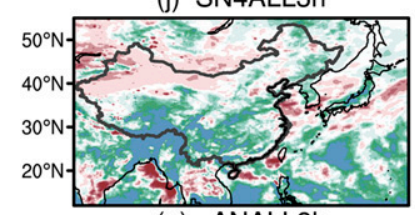

(n) ANALL3h

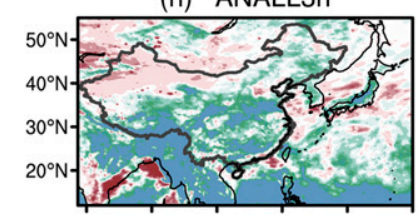

$75^{\circ} \mathrm{E} \quad 90^{\circ} \mathrm{E} 105^{\circ} \mathrm{E} 120^{\circ} \mathrm{E} 135^{\circ} \mathrm{E} 150^{\circ}$

(c) $\mathrm{SN}^{75^{\circ} \mathrm{E}} \mathrm{UV}^{9}$

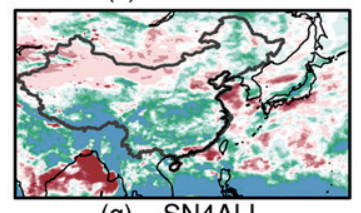

(g) SN4ALL

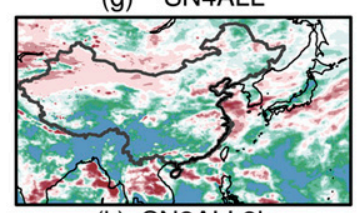

(k) SN2ALL3h

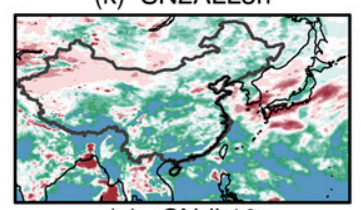

(o) SNdk10

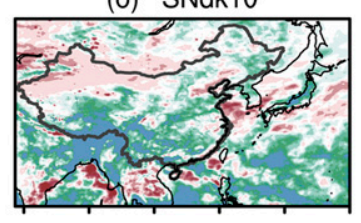

(a) CMORPH

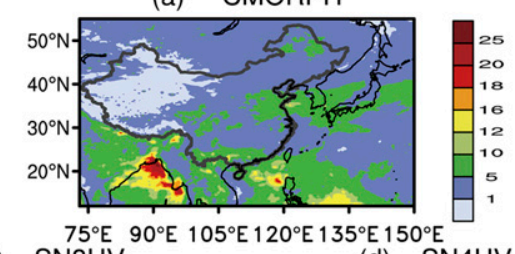

(d) SN4UV

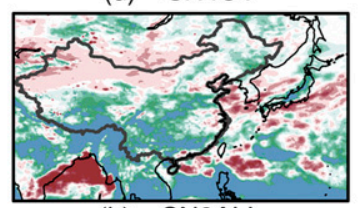

(h) SN2ALL

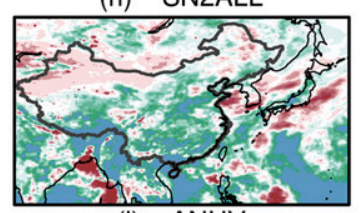

(I) ANUV

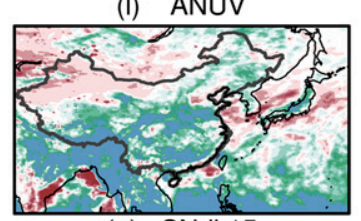

(p) SNdk15

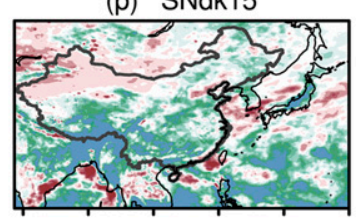

(e) SN2UV

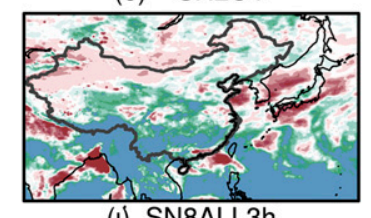

(I) SN8ALL3h

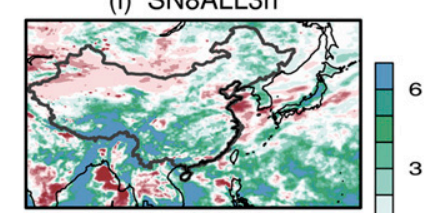

(m) ANALL

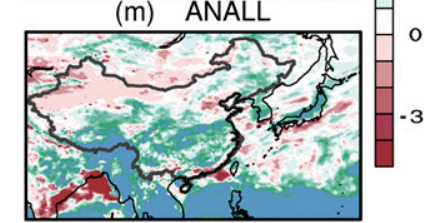

(q) SNdk20

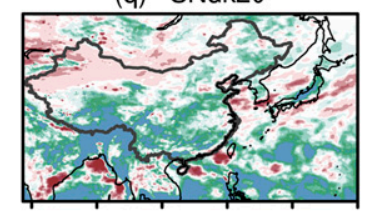

FIG. 2. (a) The averaged precipitation in JJA 2003 over EA (mm·day ${ }^{-1}$ ) for CMORPH; (b)-(q) the bias between 16 experiments and CMORPH.

intensified rainfall belts in YRB, with larger positive bias over $8 \mathrm{~mm} \cdot$ day $^{-1}$.

The regional differences among the individual experiment can be reflected by spatial quantitative metrics. Three statistic metrics, the root-mean-error square (RMSE), correlation $R$, and standard deviation (Sd), were applied, and they are shown as a Taylor diagram for the mean JJA precipitation distribution over six subregions (Fig. 3). The improvement from interior nudging over the control run was evident in almost all subregions with largely reduced RMSEs (Figs. 3b-f). In EA domain, CTL performed the least successfully, with an $R$ of 0.52 and RMSE of 2.13 .

To determine the impact of nudging parameters on precipitation intensity, the observed and simulated frequencies of JJA mean precipitation intensity were shown in Fig. 4. The spectra of JJA precipitation intensity for the WRF standard run shifted toward the higher end of spectrum (Figs. 4a,b), leading to the largest overestimation by over $20 \%$ for heavy rain $\left(10-20 \mathrm{~mm} \cdot\right.$ day $\left.^{-1}\right)$ and very heavy rain $\left(>20 \mathrm{~mm} \cdot \mathrm{day}^{-1}\right)$ over EA and SC (Figs. S1a and $\mathrm{S} 1 \mathrm{~b}$ in the online supplemental material). By employing the interior nudging techniques, the WRF Model could obviously reduce the overestimation of heavy rainfall events, which might largely be attributed to the correct reproduction of the circulation of monsoon (Fig. 8). AN experiments exhibited worse than SN experiments in YRB with considerable overestimation ranging from $19.48 \%$ to $25.97 \%$ for heavy rainfall events, which indicated that the impact of cutoff wavelengths was significant in the area where both the largescale and mesoscale circulation can strongly affect the regional climate.

\section{2) THE IMPACT OF NUDGING VARIABLES IN SN AND AN EXPERIMENTS}

The choice of nudging variables is a decisive factor for the adjustment of large-scale fields. In SN experiments, nudging solely the kinematic variables reduced the positive biases of JJA precipitation, and nudging both 

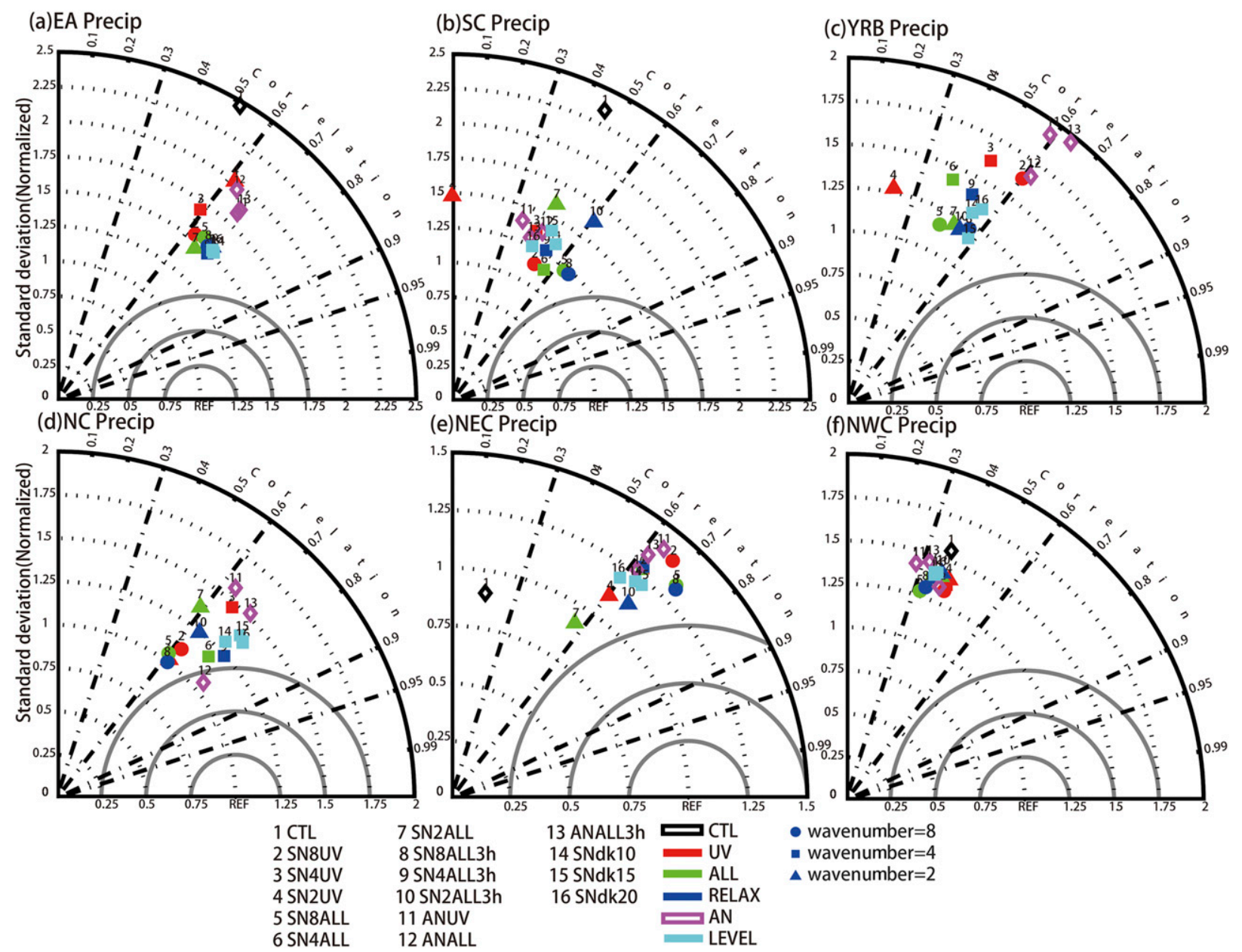

(c)YRB Precip

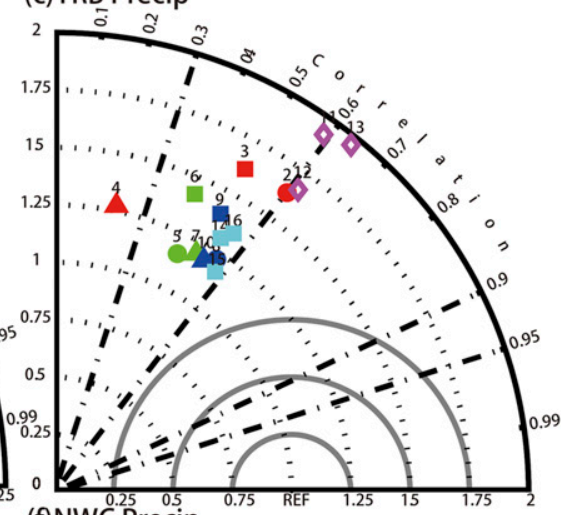

(f) NWC Precip

FIG. 3. Taylor diagrams for the average of JJA precipitation of 16 experiments against CMORPH over six subregions in 2003. Six experiment groups are identified with colors: black for CTL, red for UV, green for ALL, blue for RELAX, purple for AN, and cyan for LEVEL. The three wavenumbers are shown with shapes: circle for eight wavenumbers, square for four wavenumbers, and triangle for two wavenumbers. Sixteen individual experiments are identified with numbers.

kinematic and thermodynamic variables improved the simulation over south China and the western tropical Pacific by about $8 \mathrm{~mm} \cdot \mathrm{day}^{-1}$. Among the three experiments of the AN group, ANALL simulated the most reasonable monsoon rainfall belts over the land, especially in YRB and SC (Fig. 2). Nudging both kinematic and thermodynamic variables, therefore, improved the simulation of JJA mean precipitation in both spectral and grid nudging.

However, the effect of nudging variables in the WRF Model exhibited regional discrepancies for JJA precipitation. It is obvious that the ALL group was superior to the UV group over YRB and SC (Figs. 3a,b). For SC, experiments 5-7 from the ALL group had larger correlations ranging from 0.46 to 0.64 than those from the UV group. Also, the ALL group represents smaller Sds of 1.16-1.43 than the UV group over YRB (Fig. 3c). But for
NWC, the UV group produced a larger correlation than the experiments in ALL group (Fig. 3f). At the same time, in grid nudging experiments, ANALL simulated the largest correlations of 0.78 and 0.39 and the lowest Sds of 1.06 and 1.34 over NC and NWC, respectively, illustrating nudging both kinematic and thermodynamic variables could improve the ability of AN experiments in simulating precipitation spatial characteristics.

\section{3) THE IMPACT OF RELAXATION TIME IN SN AND AN EXPERIMENTS}

The nudging term is scaled by a relaxation time (coefficient) to control the magnitude of adjustment of the model to observation. The larger the relaxation time is, the weaker the simulation approaches observed fields, and vice versa. The RELAX group simulated larger precipitation than the ALL group, indicating that the 

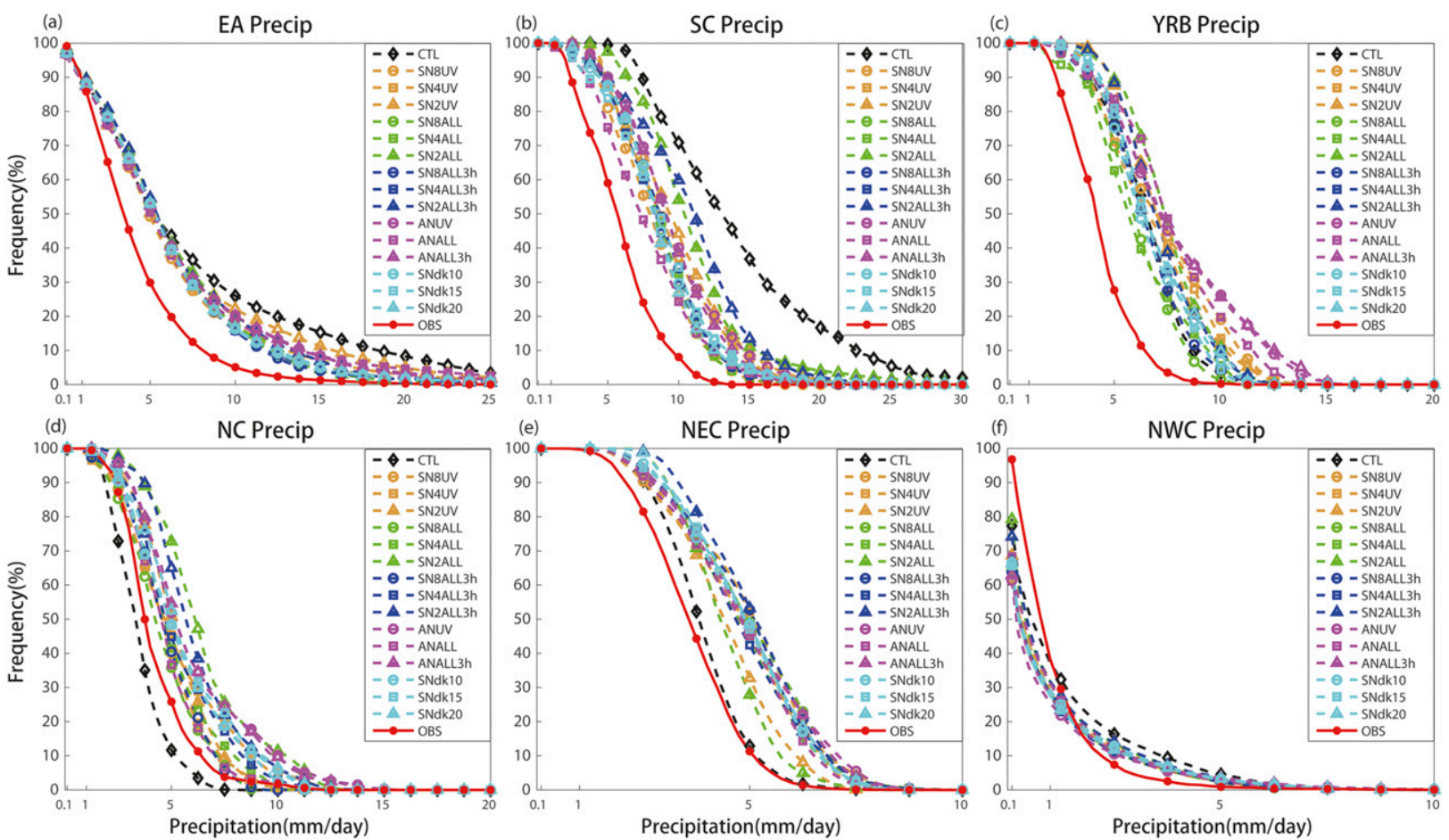

FIG. 4. Frequency (\%) of daily precipitation intensity for CMORPH observation and 16 experiments averaged over six subregions in JJA 2003. The observation and six experiment groups are identified with colors: red for observation, black for CTL, orange for UV, green for ALL, blue for RELAX, purple for AN, and cyan for LEVEL.

strength of nudging coefficient (relaxation time) can have a direct effect on the intensity of precipitation in NEC (Fig. 2). Similar performance was shown in AN experiments, as ANALL decreased the overestimation of precipitation amount over YRB and SC relative to ANALL3h (Figs. 2m,n). The results showed that larger relaxation time tends to produce larger rainfall amount for both interior nudging techniques.

\section{4) THE IMPACT OF WAVENUMBERS IN SN EXPERIMENTS}

The inner-group differences of the UV, ALL, and RELAX groups reflected the effect of selected cutoff waves in spectral nudging. As shown in Fig. 2, the nudgingfirst-two-wavenumber runs tended to have a larger bias with other parameters controlled. It is also indicated that with smaller nudging wavenumber and longer wavelength than $2000 \mathrm{~km}$, the model-generated small-scale bias may not be constrained properly in the inner domain, which may affect the precipitation amounts.

Statistically, the SN2UV experiment exhibited the lowest correlation in the UV group over most of the subregions and displayed the largest Sds and RMSs over EA and SC. The exception is over NWC, where the climate is drier and controlled by westerlies. Also, the inner-group differences in the UV group were larger than those in the ALL group over SC and YRB, indicating that the choice of wavenumbers can be more important when nudging wind alone in areas that are affected by monsoons as well as convective systems (Figs. 3b,c).

The option of wavenumbers in spectral nudging appeared to be the key factor when simulating the JJA precipitation frequency in 2003 over the monsoonaffected subregions. Selecting four and eight nudging wavenumbers could reduce the WRF bias by about $10 \%-30 \%$ for light rain in NC and YRB relative to the SN experiments that were nudging with two wavenumbers. In particular, the effect of nudging wavenumbers was more distinct over SC, as shown by a larger overestimation of $34.76 \%-49.56 \%$ for heavy rainfall events shown by the SN experiments nudging with the first two wavenumbers versus other experiments nudging with the first four or first eight wavenumbers. This result indicates that suitable cutoff wavelengths could avoid having the model derive from large-scale fields and could decrease the accumulated error from the physics in the model interior space.

In general, the wavenumber in $\mathrm{SN}$ experiments and the choice of variables in $\mathrm{SN}$ and $\mathrm{AN}$ experiments can significantly affect the model's ability in modeling precipitation spatial distribution and heavy rainfall events. 

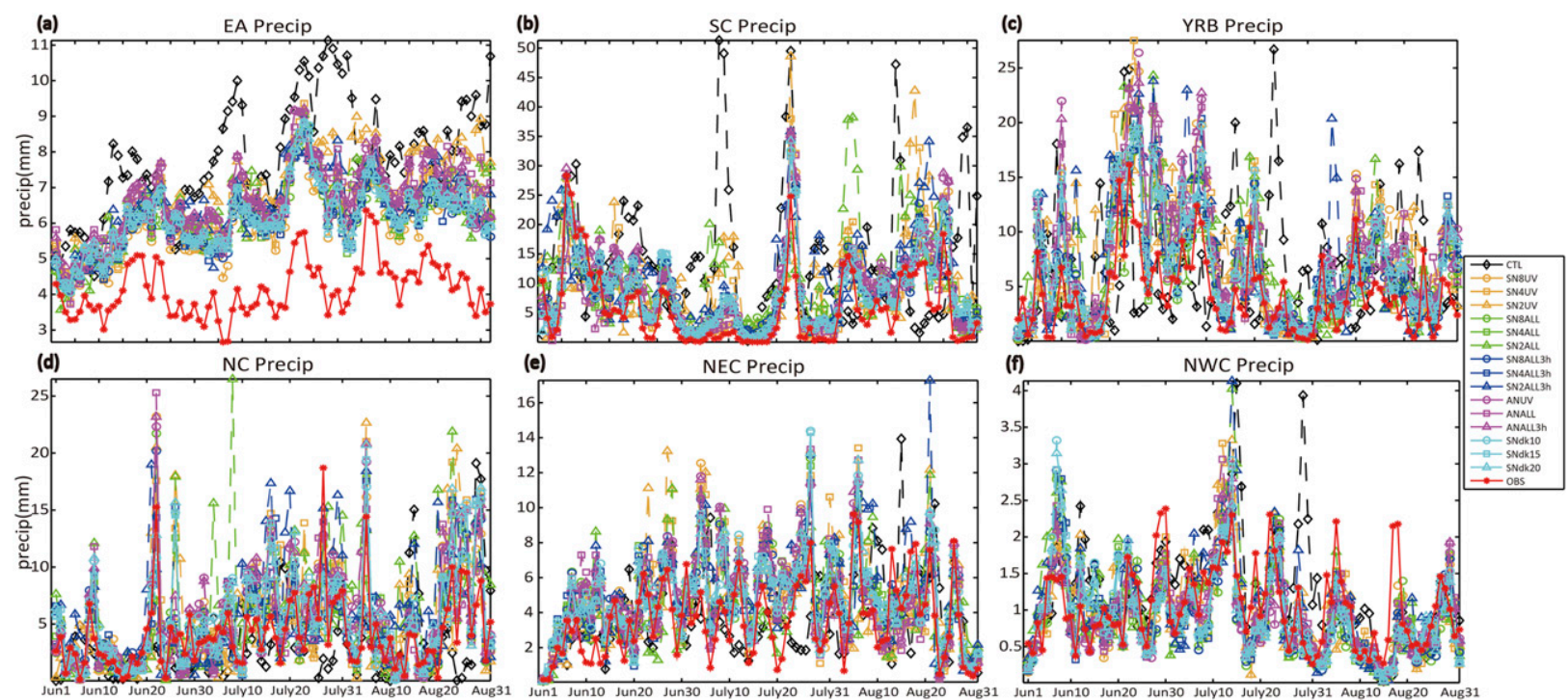

FIG. 5. Time series of spatially averaged daily rainfall $(\mathrm{mm})$ for CMORPH and 16 experiments over six subregions in JJA 2003. The observation and six experiment groups are identified with the same colors as in Fig. 4.

\section{b. The temporal variance of precipitation}

Proper reproduction of East Asian monsoon precipitation propagation and temporal variabilities is the most critical category for climate models. The subseasonal evolution of daily precipitation average (Fig. 5) and its corresponding Kullback-Leibler symmetrized divergence (KL divergence; Kullback and Leibler 1951) (Fig. 6) over the six subregions were analyzed to examine the impact of nudging parameters on the processes of rainfall events in regional scales.

For two variables $p(i)$ and $q(i)$,

KL divergence $=\frac{1}{2}\left[\sum p(i) \log \frac{p(i)}{q(i)}+\sum q(i) \log \frac{q(i)}{p(i)}\right]$.

Given that the effect of interior nudging was salient to the east of $105^{\circ} \mathrm{E}$ as mentioned above, the latitude-time cross section of precipitation between $107^{\circ}$ and $123^{\circ} \mathrm{E}$ (Fig. 7) can give us an insight into the march of modeled monsoon rainfall in the area where the heavy and extreme precipitation events mainly occurred.

\section{1) The impact of Nudging Methods}

Both SN and AN techniques can reduce the overestimation of daily precipitation amount and correct the bias in main rainfall events over almost all subregions. As depicted in Fig. 5a, the experiments with the interior nudging methods agreed better with the observed temporal variation for precipitation in JJA 2003 over the EA domain, particularly in SC, YRB, and NWC. For instance, CTL simulated large rainfall episodes on
15-22 June and 5-12 July in South China (Fig. 5b). The errors in both rain amount and temporal variation were greatly corrected in all the nudging experiments. Intuitively, smaller KL divergences of 9.53-475.68 were obtained by experiments employing $\mathrm{SN}$ and $\mathrm{AN}$ as compared with the KL divergences of CTL run being 23.14-1225.61 over all subregions (Fig. 6).

At the same time, the absence of interior nudging would lead to a wrong representation of the monsoon rainfall belts. Examining the time-latitude cross section of observed rainfall migration averaged over the region between $107^{\circ}$ and $123^{\circ} \mathrm{E}$, it can be seen that the rainstorms (Fig. 5c) were closely linked to the stages of monsoon rainfall migration. As shown in Fig. 7a, the five observed rainstorms (indicated as E1-E5 in Fig. 7a) occurred continuously from 21 to 23 June, 26 to 27 June, 29 June to 6 July, 8 to 13 July, and 17 to 22 July. The marching of rainband between $27^{\circ}$ and $35^{\circ} \mathrm{N}$ from 21 June to 22 July was absent in CTL (Fig. 7b) but was reasonably reproduced in all nudging experiments (Figs. 7c-q). Yet, all experiments had simulated rainbands extending from $17^{\circ}$ to $26^{\circ} \mathrm{N}$ after $15 \mathrm{July}$, leading to the overestimation of rainfall events in SC as shown in Fig. 5b.

\section{2) THE IMPACT OF NUDGING VARIABLES IN SN AND AN EXPERIMENTS}

It turned out that the effect of nudging variables on time evolution of precipitation also showed regional dependence in the summer of 2003. Again, nudging both kinematic and thermodynamic variables had an obvious advantage over nudging solely the kinematic variables 


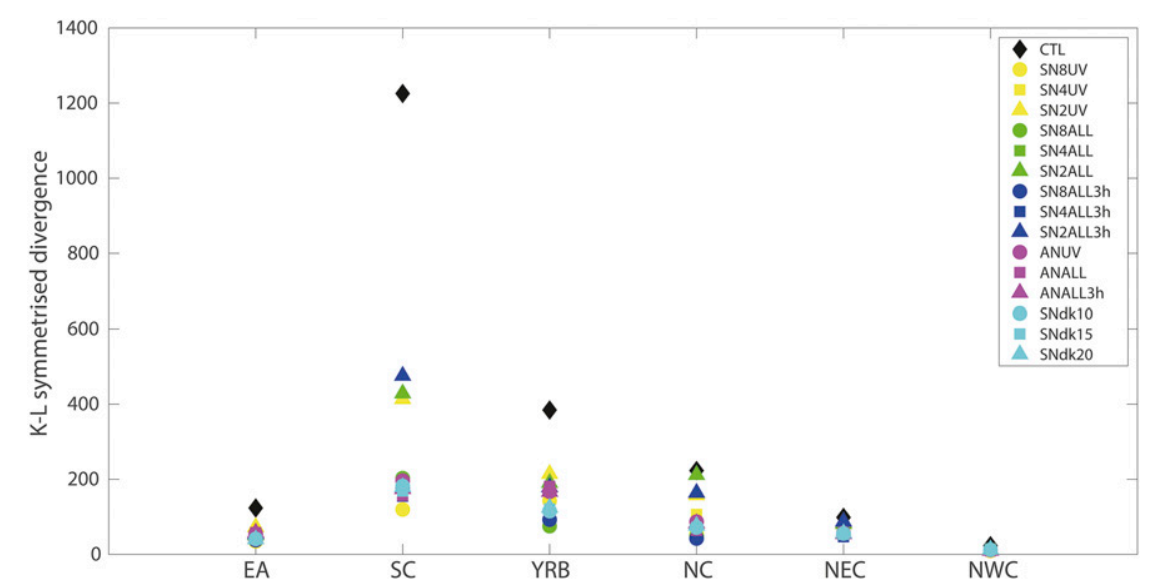

FIG. 6. The Kullback-Leibler symmetrized divergence for time series of spatially averaged daily rainfall for 16 experiments against CMORPH over six subregions in summer 2003. The six experiment groups are identified with the same colors as in Fig. 4.

for the performance of subseasonal precipitation in YRB, where the KL divergences of 75.30, 97.37, and 190.58 for SN8ALL, SN4ALL, and SN2ALL runs were all smaller than SN8UV, SN4UV, and SN2UV, respectively (Fig. 6). The improvements from increasing wavenumbers of the ALL groups were not as prominent as in UV group over SC and YRB, illustrating that spectrally nudging thermodynamic variables can reduce the model's dependence on the option of wavenumbers, particularly in the regions where both the large-scale and small-scale circulations are significant. In addition, the ANUV run had larger KL divergences of 11.79-196.39 than ANALL with KL divergences of 9.50-157.24 over most subregions except NWC. As compared with the experiments nudging wind components alone, the ALL group represented the magnitude of the main rainstorms more reasonably during mid-June to mid-July (E1-E4) in YRB (Fig. 7). It was implied that with all variables

(a) CMORPH Precip
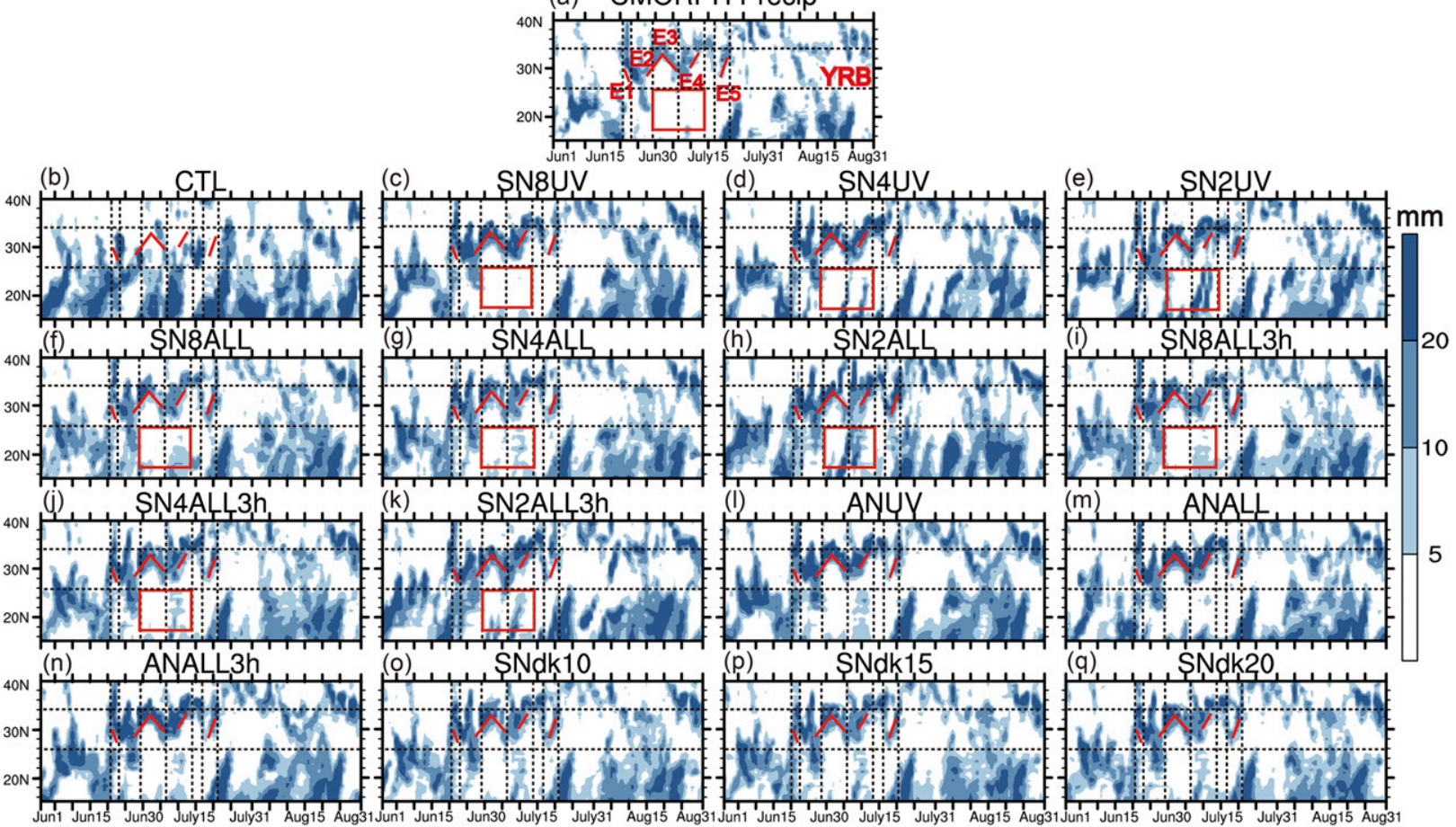

FIG. 7. Seasonal march of major East Asia monsoon rainband for CMORPH and 16 experiments over EA in summer 2003. 
spectrally nudged the WRF Model can simulate the intensity of monsoon-related rainfall better.

\section{3) THE IMPACT OF WAVENUMBERS IN SN EXPERIMENTS}

The temporal evolution was most sensitive to the choice of nudging wavenumbers in spectral nudging experiments as SN2UV, SN2ALL, and SN2ALL3h produced larger overestimation in rainy days than any other nudging experiment over all subregions. Quantitatively, the three experiments nudging the first two wavenumbers (SN2UV, SN2ALL, and SN2ALL3h) showed larger KL divergences than any other SN experiment over almost all subregions except NWC. And SN8UV's simulations were closer to observation with the smallest KL divergences ranging from 9.43 to 142.80 in UV group over all subregions, which illustrated that increasing wavenumber can improve the performance of the WRF Model to reproduce subseasonal features when spectrally nudging the wind alone.

The effect of nudging wavenumbers was outstanding for representing the migration of monsoons as well. The northward propagations of precipitation in SN2UV, SN2ALL, and SN2ALL3h were much stronger than observation and other SN simulations, which implied that nudging waves longer than $1000 \mathrm{~km}$ can improve the model's ability to reproduce precipitation. For example, in Figs. $7 \mathrm{e}, 7 \mathrm{~h}$, and $7 \mathrm{k}$, the simulated rainbands exhibited a strong but false development over the area between $18^{\circ} \mathrm{N}$ and $26^{\circ} \mathrm{N}$ from 29 June to 13 July, when the consecutive rainstorm episodes (E3 and E4 in Fig. 7a) occurred in YRB for the CMORPH dataset.

Overall, the nudging methods, variables, and wavenumbers had obvious impacts on the temporal variance of precipitation, especially in the subregions that are affected by monsoon and active convection.

\section{c. Verification of large-scale fields}

Considering the critical roles of the lower-level circulation and moisture transport to monsoon precipitation, the $700-\mathrm{hPa}$ wind fields were assessed to show the skill of interior nudging on reproducing the monsoon circulation. To quantify the moisture budget, the divergence of observed and simulated water vapor flux at $700 \mathrm{hPa}$ were calculated (Fig. 8). We calculated the divergence of water vapor flux by the formula

$$
\nabla(V q)=\frac{\partial}{\partial x}(u q)+\frac{\partial}{\partial y}(v q),
$$

where $q$ denotes the specific humidity, and $u$ and $v$ denote wind components at $700 \mathrm{hPa}$. The bias fields were provided in Figs. 8b-q. The vertical structure of large-scale circulation by various experiments and impact of nudging parameters were examined with correlation analysis (Fig. 9). To better understand the monsoonrelated rainfall migration and the precipitation time evolution, time series of correlation for the circulation at 700 and $200 \mathrm{hPa}$, geopotential height and temperature at $500 \mathrm{hPa}$ were calculated over the monsoon-dominated area (Fig. 10). The analyzed region in Fig. 10 was the same as Fig. 7.

\section{1) The IMPACT OF NUdGing Methods}

Relative to JRA-55 observation, the anticyclone on the west Pacific in CTL run shifted eastward, leading to the cyclonic wind bias at the east part of CORDEX-EA domain and a drying condition over the east of China and the East China Sea. Consequently, the observed convergence center of water vapor flux over YRB shifted eastward obviously in CTL run, resulted in the negative correlation between CTL precipitation and observation over YRB (Fig. 3c) and obvious underestimation of rainfall amount over NC (Fig. 2b). Such errors in the wind field were greatly corrected in all interior nudging runs, especially for the low-level anticyclone system over the western Pacific (Figs. 8c-q).

Vertically, the improvement of nudging methods was also evident for JJA mean wind components and moisture at different levels (Fig. 9). Compared to the CTL run, nudging experiments exhibited larger correlation coefficients for both $U$ and $V$ wind components and specific humidity below $500 \mathrm{hPa}$, particularly in the monsoon-dominated wet regions such as SC. Similar performance was found for the low-level and upperatmospheric circulation over the monsoon-dominated region, with CTL producing the smallest correlations (Fig. 10). Such model behavior partially determined the deviation in temporal evolution of modeling precipitation over SC and YRB (Fig. 5). Meanwhile, the profiles from $\mathrm{SN}$ experiments nudging with first four and eight wavenumbers were closer to JRA-55 than the AN runs at lower atmosphere, associated with better precipitation pattern (Fig. 9).

\section{2) THE IMPACT OF NUDGING VARIABLES IN SN AND AN EXPERIMENTS}

In Fig. 8, it is obvious that the modeled wind fields of the ALL and UV groups resembled each other, although the bias of divergence was clearly different. Nudging both kinematic and thermodynamic variables in SN experiments simulated better water vapor transportation originating from Bengal Bay, with less divergence bias over Bengal Bay, the western Pacific Ocean, and YRB than those nudging-wind-only experiments. It was indicated that the dependence of vapor 


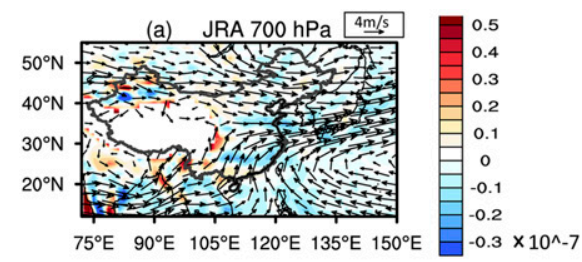

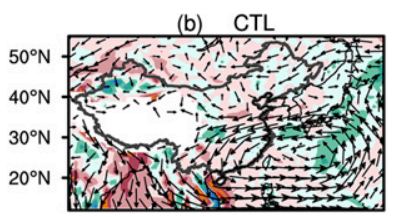

(f) SN8ALL

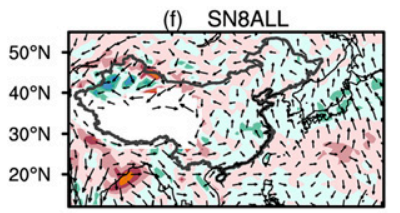

(j) SN4ALL3h

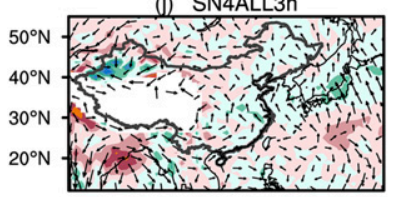

(n) ANALL3h

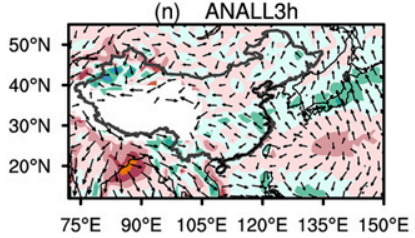

(c) SN8UV

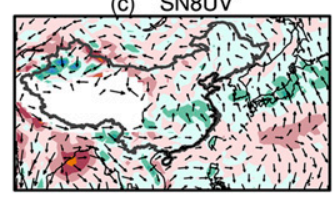

(g) SN4ALL

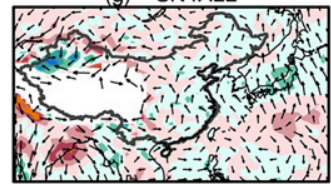

(k) SN2ALL3h

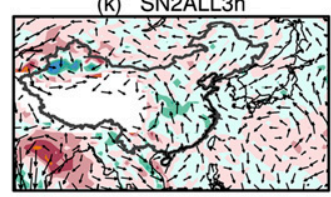

(o) SNdk10

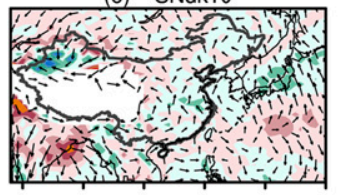

$75^{\circ} \mathrm{E} \quad 90^{\circ} \mathrm{E} \quad 105^{\circ} \mathrm{E} 120^{\circ} \mathrm{E} 135^{\circ} \mathrm{E} 150^{\circ} \mathrm{E}$

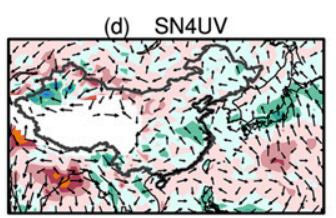

(h) SN2ALL

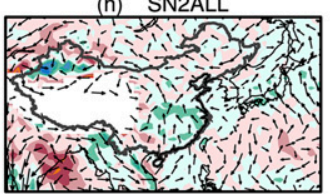

(I) ANUV

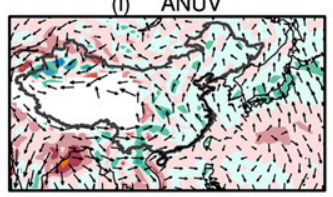

(p) SNdk15

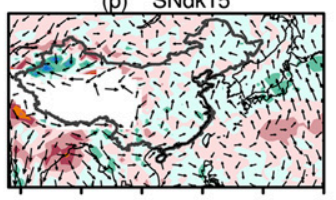

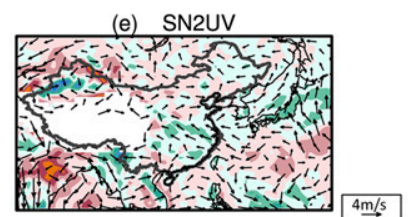

(i) SN8ALL3h

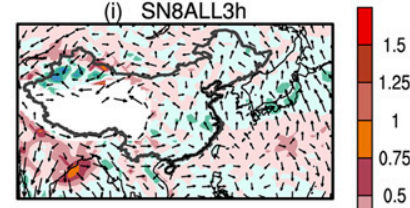

(m) ANALL

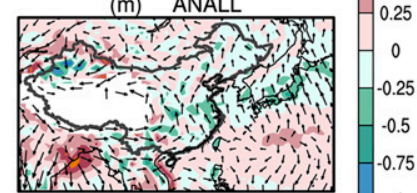

(q) SNdk20

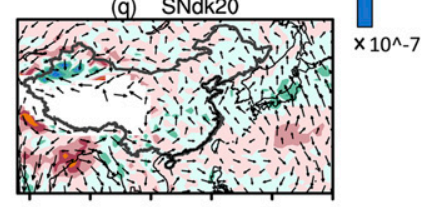

$75^{\circ} \mathrm{E} \quad 90^{\circ} \mathrm{E} \quad 105^{\circ} \mathrm{E} \quad 120^{\circ} \mathrm{E} 135^{\circ} \mathrm{E} \quad 150^{\circ} \mathrm{E}$

FIG. 8. (a) The averaged wind fields (vectors) and water vapor flux divergence (color shades; $\mathrm{g} \cdot \mathrm{cm}^{-2} \cdot \mathrm{hPa} \mathrm{h}^{-1} \cdot \mathrm{s}^{-1}$ ) at $700 \mathrm{hPa}$ over $\mathrm{EA}$ in summer 2003 for JRA-55 observation; (b)-(q) the corresponding bias plot for the 16 experiments against observation.

transportation at low atmosphere on wind fields was weaker when nudging both kinematic and thermodynamic variables than nudging wind alone, which provided a good explanation for larger inner-group differences in UV group than in ALL group for modeling precipitation patterns over SC and YRB (Figs. 3b,c).

Meanwhile, the wind components at various levels were sensitive to the nudging variables. The ALL group reproduced the spatial pattern for wind more reasonably than the UV group from 900 to $200 \mathrm{hPa}$ over all subregions, particularly for the $v$-wind component. Nudging both kinematic and thermodynamic variables combined with nudging first four and eight wavenumbers could provide larger correlations for circulation at 200 and $700 \mathrm{hPa}$ in the monsoon-related region over the whole summer (Fig. 10).

\section{3) THE IMPACT OF RELAXATION TIME IN SN AND AN EXPERIMENTS}

When simulating moisture, the choice of relaxation time was more important in grid nudging technique. In AN experiments, nudging coefficient affected the stronger divergence of the western Pacific subhigh and its corresponding circulation in the ANALL3h run (Figs. $8 \mathrm{~m}, \mathrm{n}$ ). Longer relaxation time induced the worst simulation of meridional wind and moisture for atmosphere below $700 \mathrm{hPa}$ in AN group (Fig. 9), which largely contributed to the positive divergence bias of the ANALL3h run over Pacific in Fig. 8.

\section{4) THE IMPACT OF WAVENUMBERS IN SN EXPERIMENTS}

The transportation of moisture from the tropical western Pacific and water convergence over YRB could be more reasonably produced in the experiments nudging with the first four or eight wavenumbers in the UV, ALL, and RELAX groups (Fig. 8). As the water vapor flux convergence provides the critical environmental condition for intense precipitation, suitable nudging wavelength could simulate more reliable moisture and large-scale circulation, thereby reproducing the distribution of heavy rainfall. However, when it comes to the low-level jet between $35^{\circ}$ and $45^{\circ} \mathrm{N}$, anticyclone over the tropical western Pacific, and divergence, increasing 

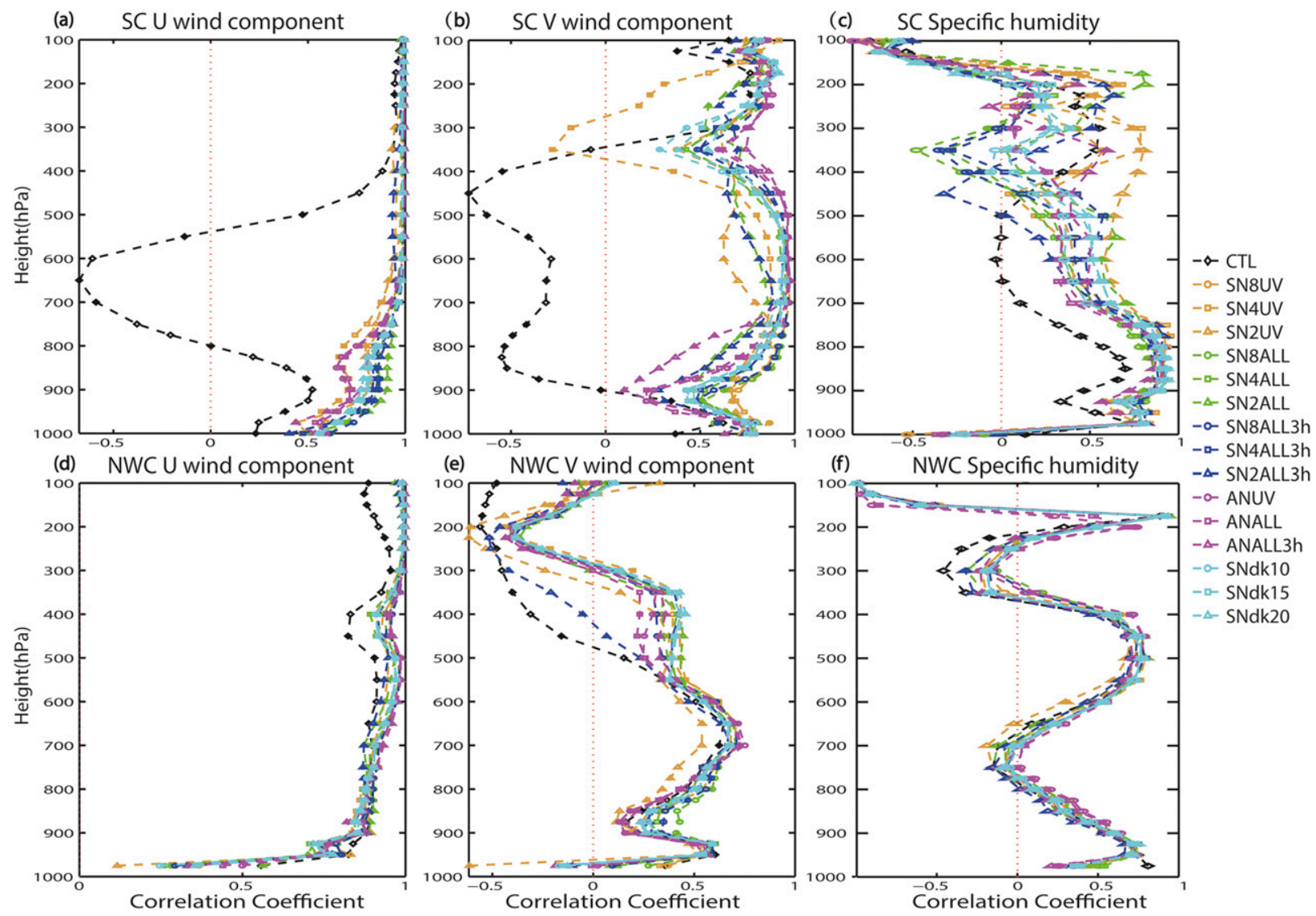

FIG. 9. Vertical profiles of the correlation coefficient for the spatial pattern of (a),(d) $U$ wind component, (b), (e) $V$ wind component, and (c),(f) specific humidity over (top) YRB and (bottom) NWC of 16 experiments against JRA-55 in summer 2003. The six experiment groups are identified with the same colors as in Fig. 4.

nudging wavenumbers from four to eight showed limited influence.

The influence of wavenumber was more obvious on circulation at various levels. It was clear that the SN experiments nudging with first two wavenumbers simulated the $v$-wind component worse than other nudging experiments in UV, ALL, and RELAX groups over most subregions (Fig. 9), particularly in the monsoonrelated region at $700 \mathrm{hPa}$ (Fig. 10).

The above analysis indicated that the application of spectral nudging with the first four or eight wavenumbers could improve the simulation of precipitation via improved simulation of large-scale circulation and moisture transportation. Also, with thermodynamic variables nudged, the large-scale fields would be closer to driving fields than nudging wind fields merely, which had a considerable influence on moisture through heating.

\section{d. Spectral analysis of wind fields}

In addition to the direct comparison to illustrate the effect of nudging parameters on circulation and thermodynamical fields, we applied a two-dimensional power spectrum via fast Fourier transformation for wind fields to quantify the model's behavior at different scales by giving the JJA mean one-dimensional wavenumber spectra (Fig. 11). To diminish the influence of lateral boundary, 30 grid points along every edge of the model domain were removed and the linear trend was subtracted following Errico (1985). Considering the influence of orography, we choose the $\sigma$-20 level as the near-surface level, which was not nudged in SN experiments. The horizontal wind fields at 700, 500, and $200 \mathrm{hPa}$ were also used here to analyze the effective resolution and nudging effect at different levels.

The atmospheric kinetic energy (KE) spectra exhibit a $k^{-5 / 3}$ dependence in the mesoscales and possesses a $k^{-3}$ dependence for the large scales. It was clear that each spectrum showed a transition from slope -3 to a shallower slope of approximately -2 and -1.6 between the wavelengths of 100 and $500 \mathrm{~km}$ at $\sigma-20$ level and $700 \mathrm{hPa}$, respectively (Figs. 11a,b). We simply define the effective resolution as the spectrum beginning to decay 
(a)

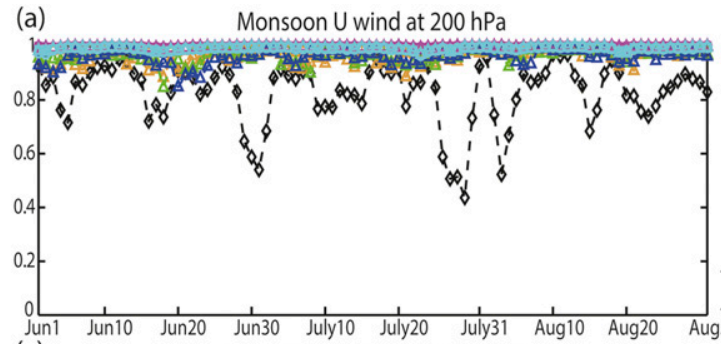

(b)

Monsoon $\mathrm{V}$ wind at $200 \mathrm{hPa}$
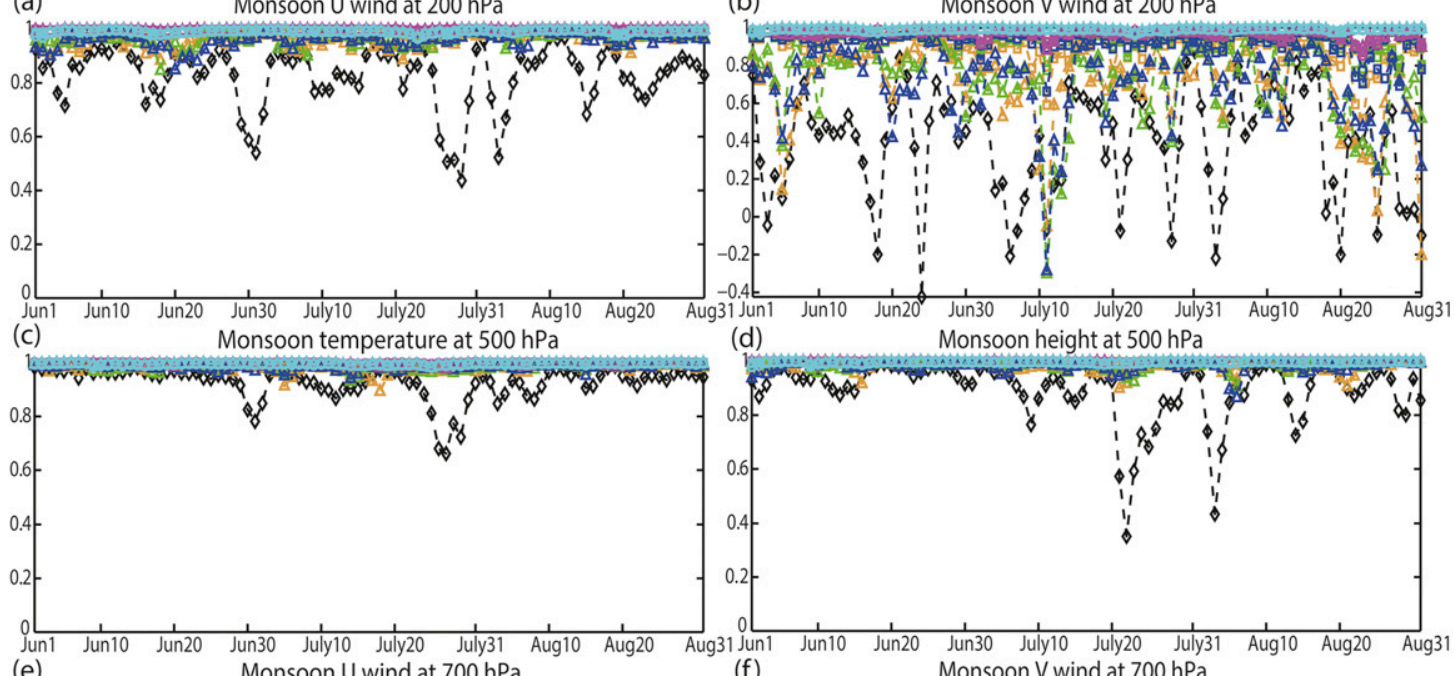

(d) Monsoon height at $500 \mathrm{hPa}$
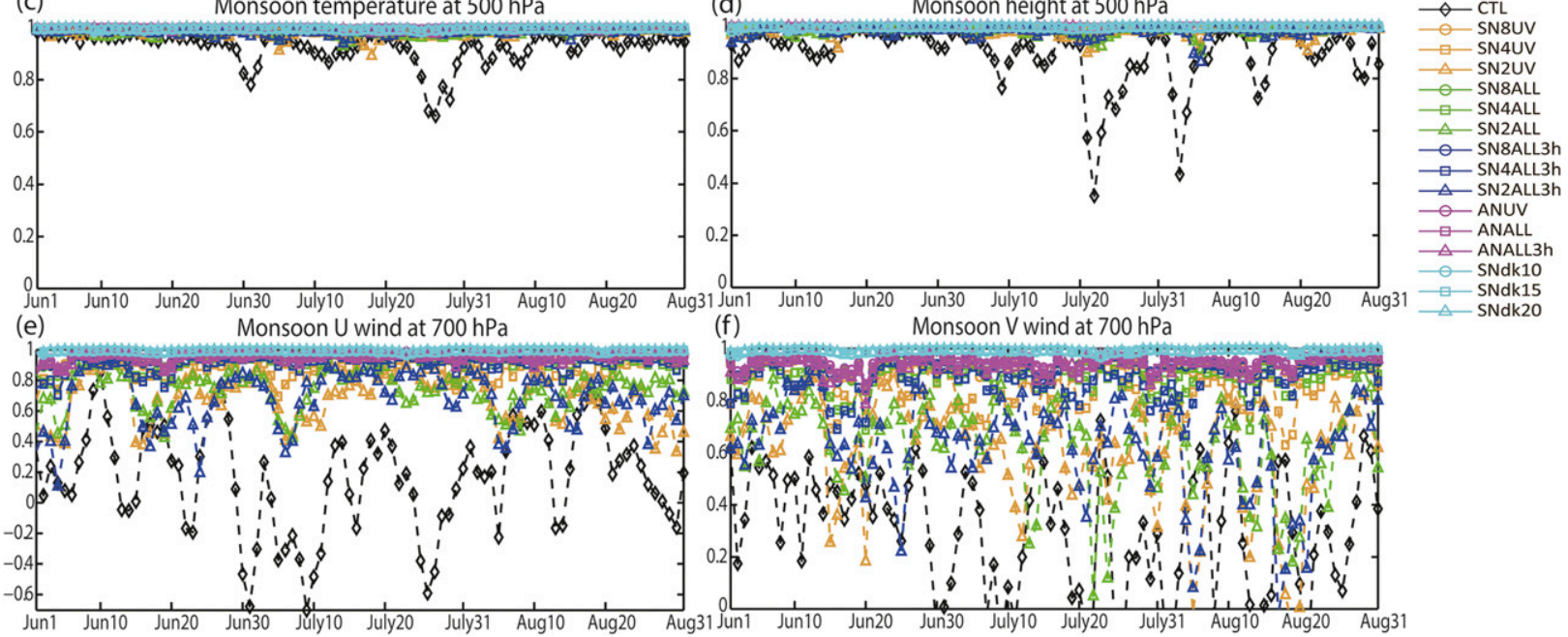

FIG. 10. Time series plots of similarity (correlation coefficient) for (a) $U$ wind at $200 \mathrm{hPa}$, (b) $V$ wind at $200 \mathrm{hPa}$, (c) geographic height at $500 \mathrm{hPa},(\mathrm{d})$ temperature at $500 \mathrm{hPa}$, (e) $U$ wind at $700 \mathrm{hPa}$, and (f) $V$ wind at $700 \mathrm{hPa}$ in summer 2003 over the EA domain between 16 experiments and JRA-55. The six experiment groups are identified with the same colors as in Fig. 4.

obviously below the $k^{-5 / 3}$ slope. When the energy spectra damped more quickly than the $k^{-5 / 3}$ slope, the model dissipation was prominent and considered dynamically inaccurate. Based on this criterion, the effective resolution could be quantified as about $100 \mathrm{~km}(4 \Delta x)$, which was higher than the results from Skamarock (2004). It implied that all WRF runs could reproduce the processes larger than $100 \mathrm{~km}$, which could not be affected by the nudging methods.

However, when comparing with other experiments, the control experiment had larger energy at a wavelength of $100-500 \mathrm{~km}$ at $700 \mathrm{hPa}$, corresponding to the smallest slope of -1.51 . Considering the resembled behavior of all experiments near the surface ( $\sigma$-20 level), it could be inferred then that the CTL produced overactive small scales activities in the PBL, which can modulate the large-scale wind fields shown in Fig. 8b. The slopes of $\mathrm{SN}$ experiments were close to each other, and the twowavenumber-nudging experiments exhibited a smaller slope of about 1.52 than any other experiment in UV, ALL, and RELAX groups at $700 \mathrm{hPa}$. The insufficient suppression for dynamical error from the PBL led to the worse performance of moisture transportation as well as precipitation simulation. The spectra of the AN group were more coincident with driving data than the SN experiments at $200 \mathrm{hPa}$, indicating that the AN group was unable to reflect the small scales at the upper atmosphere. Note that the energy spectra of ERA decayed faster than $k^{-5 / 3}$, which was inappropriate because of its limited resolution.

\section{Summary and discussion}

In this paper, the impact of two interior nudging methods on the JJA 2003 precipitation was assessed over CORDEX-EA-II domain using 16 experiments. First of all, analysis showed that the experiments with the interior nudging methodology displayed evident advantages over the control run for both spatial and temporal characteristics of precipitation, especially the heavy rainfall events. Comparably, the interior nudging showed little improvement for light rainfall events, which might be largely attributed to the accumulated model error from physics.

In general, the $\mathrm{SN}$ experiments could reproduce the JJA mean precipitation pattern more reasonably than the AN experiments. The faster-damped energy spectra at upper atmosphere and lower correlations for circulation 

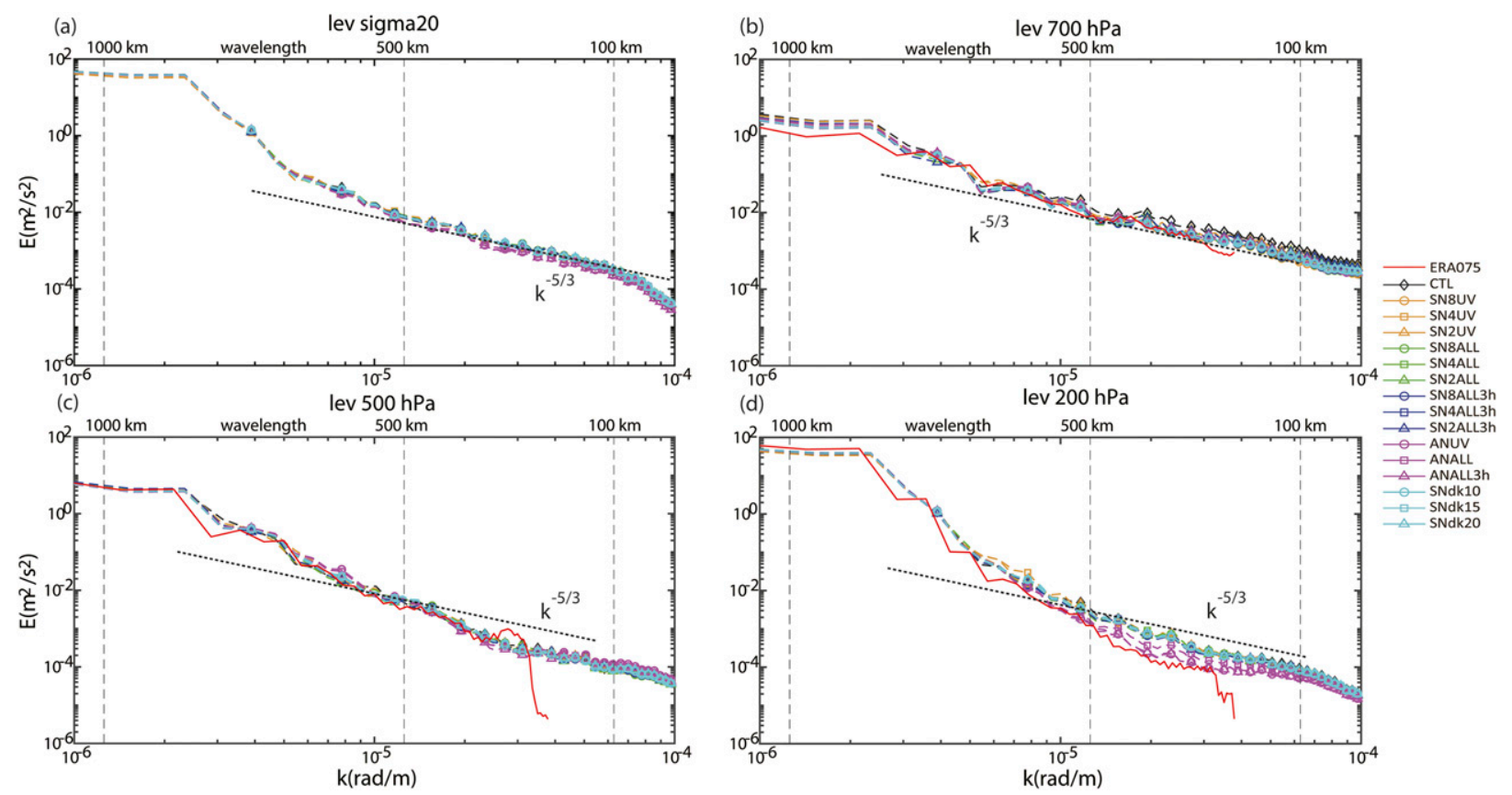

FIG. 11. Kinetic energy spectra of JJA mean horizontal wind velocities for 16 experiments and ERA-interim driving fields at (a) $\sigma$-20 level (no driving field) and (b) 700 , (c) 500 , and (d) $200 \mathrm{hPa}$. The dotted line corresponds to a $-5 / 3$ slope. The six experiment groups are identified with the same colors as in Fig. 4.

at low atmosphere from the AN experiments reflected that the circulation in AN experiments was overforced to the driving fields at the upper atmosphere, which further suppressed the meso-to-small scales at the surface and could worsen the wind and moisture fields. With cutoff wavelengths, the model approaches observation in large scales and preserves small-scale physical processes. Thus, we propose that it is better to apply spectral nudging when simulating the subseasonal climate, especially in the regions where are controlled by both large-scale and small-scale processes.

Second, the results also showed that the JJA 2003 precipitation was most sensitive to the choice of wavenumbers in spectral nudging experiments for the EA domain. Nudging wavenumbers determines the scale of wave affected by spectral nudging in model spectral space. The roles of nudging parameters were displaying a regional dependence for reproducing subseasonal features of the JJA precipitation. In the regions of SC and YRB where both large-scale circulation and mesoscale systems have a combined influence on the weather and climate, nudging properly chosen wavelengths plays a more essential role for short-term rainfall events. It was quite reasonable that, in the place controlled by largescale processes, even with long cutoff wavelengths, the model error largely could be compensated. Also, for most of the subregions, the SN experiments nudging with the first four wavenumbers were good enough to reproduce both small- and large-scale atmospheric states at low levels. For the CORDEX-EA domain, the appropriate nudging wavelength is around $1000 \mathrm{~km}$ to simulate East Asian monsoon propagation and associated precipitation events.

Third, spectrally nudging both kinematic and thermodynamic variables can improve the model's skill in modeling wind and moisture fields at various atmospheric levels more obviously than nudging merely kinematic variables. With thermodynamic variables nudged, the dependence of modeling thermodynamic field on the wind fields via geostrophic adjustment might be weakened, and the moisture transport could be affected via heating. And the improvement from increasing nudging wavenumbers can be more outstanding when nudging merely kinematic variables than nudging kinematic as well as thermodynamic variables.

Fourth, comparing the impact of nudging variables and relaxation time in the $\mathrm{AN}$ and $\mathrm{SN}$ experiments, the choice of nudging variables affected precipitation and circulation modeling efficiently for spectral nudging, while the option of relaxation time showed more contribution to the modeled precipitation for grid nudging. Because of the cutoff wavelengths, the SN experiments could adapt the wind fields to pressure fields via the geostrophic adjustment in small scales. It might be the reason why nudging all variables spectrally showed little improvement for the precipitation pattern over drier 
subregions where are influenced by large-scale circulation strongly. It was sufficient for the WRF Model to reduce simulated circulation deviation through winds nudged and corresponding geostrophic adjustment over the region that is controlled by westerlies, such as NWC. Comparably, the effect of relaxation time cannot be neglected for AN experiments, which determines the nudging strength of nudging variables. With a 3-h relaxation time, the simulated rainfall would depend on model physics in the PBL to a large degree, and the deviation between model physics and driving fields could not obtain enough compensation at each grid. The error accumulated along with time and affected short-term convective processes that were finally shown as the overestimation of rainfall amount. However, little innergroup difference was shown among LEVEL experiments, indicating that starting nudging from the planetary boundary layer was enough for the WRF Model to simulate climates and to free the regional model dynamics to produce small-scale processes near the surface.

Acknowledgments. This research was supported by the National Key Research and Development Program of China (2018YFA0606003 and 2017YFA0603803), the National Natural Science Foundation of China (41575099 and 41505057), and the Open Science Foundation of State Key Laboratory of Severe Weather (2015LASW-A04).

\section{REFERENCES}

Boberg, F., P. Berg, P. Thejll, W. J. Gutowski, and J. H. Christensen, 2010: Improved confidence in climate change projections of precipitation further evaluated using daily statistics from ensembles models. Climate Dyn., 32, 1097-1106, https://doi.org/10.1007/s00382-008-0446-y.

Bowden, J. H., T. L. Otte, C. G. Nolte, and M. J. Otte, 2012: Examining interior grid nudging techniques using two-way nesting in the WRF Model for regional climate modeling. J. Climate, 25, 2805-2823, https://doi.org/10.1175/JCLI-D-11-00167.1.

Cha, D. H., and D. K. Lee, 2009: Reduction of systematic errors in regional climate simulations of the summer monsoon over East Asia and the western North Pacific by applying the spectral nudging technique. J. Geophys. Res., 114, D14108, https://doi.org/10.1029/2008JD011176.

,$- \ldots$, and S. Y. Hong, 2008: Impact of boundary layer processes on seasonal simulation of the East Asian summer monsoon using a regional climate model. Meteor. Atmos. Phys., 100, 53-72, https://doi.org/10.1007/s00703-008-0295-6.

— C. S. Jin, D. K. Lee, and Y. H. Kuo, 2011: Impact of intermittent spectral nudging on regional climate simulation using Weather Research and Forecasting Model. J. Geophys. Res., 116, D10103, https://doi.org/10.1029/2010JD015069.

Chen, F., and J. Dudhia, 2001: Coupling an advanced land surface-hydrology model with the Penn State-NCAR MM5 modeling system. Part I: Model implementation and sensitivity. Mon. Wea. Rev., 129, 569-585, https://doi.org/10.1175/ 1520-0493(2001)129<0569:CAALSH > 2.0.CO;2.
Chen, G., T. Iwasaki, H. Qin, and W. Sha, 2014: Evaluation of the warm-season diurnal variability over East Asia in recent reanalyses JRA-55, ERA-Interim, NCEP CFSR, and NASA MERRA. J. Climate, 27, 5517-5537, https://doi.org/10.1175/ JCLI-D-14-00005.1.

Collins, W.D., and Coauthors, 2004: Description of the NCAR Community Atmosphere Model (CAM 3.0). NCAR Tech. Note NCAR/TN-464+STR, 214 pp., https://doi.org/10.5065/ D63N21CH.

Dee, D. P., and Coauthors, 2011: The ERA-Interim reanalysis: Configuration and performance of the data assimilation system. Quart. J. Roy. Meteor. Soc., 137, 553-597, https://doi.org/ 10.1002/qj.828.

Domínguez, M., and Coauthors, 2013: Present-climate precipitation and temperature extremes over Spain from a set of high resolution RCMs. Climate Res., 58, 149-164, https://doi.org/ 10.3354/cr01186.

dos Santos, M. J., M. A. F. S. Dias, and E. D. Freitas, 2014: Influence of local circulations on wind, moisture, and precipitation close to Manaus City, Amazon Region, Brazil. J. Geophys. Res. Atmos., 119, $13233-13249$, https://doi.org/10.1002/ 2014JD021969.

Ebita, A., and Coauthors, 2011: The Japanese 55-year reanalysis "JRA-55": An interim report. SOLA, 7, 149-152, https:// doi.org/10.2151/sola.2011-038.

ECMWF, 2009: ERA-Interim Project (updated monthly). National Center for Atmospheric Research Computational and Information Systems Laboratory Research Data Archive, accessed 6 August 2017, https://doi.org/10.5065/D6CR5RD9.

Errico, R. M., 1985: Spectra computed from a limited area grid. Mon. Wea. Rev., 113, 1554-1562, https://doi.org/10.1175/ 1520-0493(1985)113<1554:SCFALA > 2.0.CO;2.

Feser, F., and M. Barcikowska, 2012: The influence of spectral nudging on typhoon formation in regional climate models. Environ. Res. Lett., 7, 014024, https://doi.org/10.1088/ 1748-9326/7/1/014024.

_- B. Rockel, H. von Storch, J. Winterfeldt, and M. Zahn, 2011: Regional climate models add value to global model data a review and selected examples. Bull. Amer. Meteor. Soc., 92, 1181-1192, https://doi.org/10.1175/2011BAMS3061.1.

Fowler, H. J., S. C. Blenkinsop, and C. Tebaldi, 2007: Linking climate change modelling to impacts studies: Recent advances in downscaling techniques for hydrological modelling. Int. J. Climatol., 27, 1547-1578, https://doi.org/10.1002/joc.1556.

Gao, X. J., and F. Giorgi, 2017: Use of the RegCM System over East Asia: Review and perspectives. Engineering, 3, 766-772, https://doi.org/10.1016/J.ENG.2017.05.019.

Giorgi, F., 2006: Regional climate modeling: status and perspectives. J. Phys. IV 139, 101-118, https://doi.org/10.1051/ jp4:2006139008.

_ C. Jones, and G. R. Asrar, 2009: Addressing climate information needs at the regional level: The CORDEX framework. WMO Bull., 58, 175-183.

Gómez, B., and G. Miguez-Macho, 2017: The impact of wave number selection and spin-up time in spectral nudging. Quart. J. Roy. Meteor. Soc., 143, 1772-1786, https://doi.org/10.1002/qj.3032.

Hanrahan, J., C. C. Kuo, and T. Y. Gan, 2015: Configuration and validation of a mesoscale atmospheric model for simulating summertime rainfall in central Alberta. Int. J. Climatol., 35, 660-675, https://doi.org/10.1002/joc.4011.

Heikkilä, U., A. Sandvik, and A. Sorteberg, 2011: Dynamical downscaling of ERA-40 in complex terrain using the WRF regional climate model. Climate Dyn., 37, 1551-1564, https:// doi.org/10.1007/s00382-010-0928-6. 
Hong, S. Y., and E. C. Chang, 2012: Spectral nudging sensitivity experiments in a regional climate model. Asia-Pac. J. Atmos. Sci., 48, 345-355, https://doi.org/10.1007/s13143-012-0033-3.

—, Y. Noh, and J. Dudhia, 2006: A new vertical diffusion package with an explicit treatment of entrainment processes. Mon. Wea. Rev., 134, 2318-2341, https://doi.org/10.1175/ MWR3199.1.

Huang, B., S. Polanski, and U. Cubasch, 2015: Assessment of precipitation climatology in an ensemble of CORDEX-East Asia regional climate simulations. Climate Res., 64, 141-158, https://doi.org/10.3354/cr01302.

Hui, P. H., J. P. Tang, S. Y. Wang, and J. Wu, 2015: Sensitivity of simulated extreme precipitation and temperature to convective parameterization using RegCM3 in China. Theor. Appl. Climatol., 122, 315-335, https://doi.org/10.1007/s00704-014-1300-2.

Jin, C. S., D. H. Cha, D. K. Lee, M. S. Suh, S. Y. Hong, H. S. Kang, and C. H. Ho, 2016: Evaluation of climatological tropical cyclone activity over the western North Pacific in the CORDEX-East Asia multi-RCM simulations. Climate Dyn., 47, 765-778, https://doi.org/10.1007/s00382-015-2869-6.

JMA, 2013: JRA-55: Japanese 55-year Reanalysis. Japan Meteorological Agency Global Environment and Marine Department Climate Prediction Division Research Data Archive, accessed 3 April 2018, https://jra.kishou.go.jp/ JRA-55/index_en.html\#download.

Joyce, R. J., J. E. Janowiak, P. A. Arkin, and P. P. Xie, 2004: CMORPH: A method that produces global precipitation estimates from passive microwave and infrared data at high spatial and temporal resolution. J. Hydrometeor., 5, 487-503, https://doi.org/10.1175/1525-7541(2004)005<0487:CAMTPG> 2.0.CO;2.

Kain, J. S., and J. M. Fritsch, 1990: A one-dimensional entraining/detraining plume model and its application in convective parameterization. J. Atmos. Sci., 47, 2784-2802, https://doi.org/10.1175/1520-0469(1990)047<2784:AODEPM> 2.0.CO;2.

Klutse, N. A. B., B. J. Abiodun, B. C. Hewitson, W. J. Gutowski, and M. A. Tadross, 2016: Evaluation of two GCMs in simulating rainfall inter-annual variability over southern Africa. Theor. Appl. Climatol., 123, 415-436, https://doi.org/10.1007/ s00704-014-1356-z.

Kulkarni, S., M. C. Deo, and S. Ghosh, 2016: Evaluation of wind extremes and wind potential under changing climate for Indian offshore using ensemble of $10 \mathrm{GCMs}$. Ocean Coastal Manage., 121, 141-152, https://doi.org/10.1016/ j.ocecoaman.2015.12.008.

Kullback, S., and R. A. Leibler, 1951: On information and sufficiency. Ann. Math. Stat., 22, 79-86, https://doi.org/10.1214/ aoms/1177729694.

Kuo, Y. H., Y. R. Guo, and E. R. Westwater, 1993: Assimilation of precipitable water measurements into a mesoscale numerical model. Mon. Wea. Rev., 121, 1215-1238, https:// doi.org/10.1175/1520-0493(1993)121<1215:AOPWMI> 2.0.CO;2.

Lake, I., W. Gutowski, F. Giorgi, and B. Lee, 2017: CORDEX Climate Research and Information for Regions. Bull. Amer. Meteor. Soc., 98, ES189-ES192, https://doi.org/ 10.1175/BAMS-D-17-0042.1.

Lee, H., and Moon, B. K., 2014: Mechanisms of the extreme temperatures and the precipitation events in the future over Korean Peninsula using CORDEX data. EGU General Assembly, Vienna, Austria, EGU, 14406, https:// meetingorganizer.copernicus.org/EGU2014/EGU2014-14406-1.pdf.
Leung, L. R., L. O. Mearns, F. Giorgi, and R. L. Wilby, 2003: Regional climate research - Needs and opportunities. Bull. Amer. Meteor. Soc., 84, 89-95, https://doi.org/10.1175/BAMS-84-1-89.

Lim, K., and S. Y. Hong, 2010: Development of an effective double-moment cloud microphysics scheme with prognostic cloud condensation nuclei $(\mathrm{CCN})$ for weather and climate models. Mon. Wea. Rev., 138, 1587-1612, https://doi.org/10.1175/ 2009MWR2968.1.

Liu, P., A. P. Tsimpidi, Y. Hu, B. Stone, A. G. Russell, and A. Nenes, 2012: Differences between downscaling with spectral and grid nudging using WRF. Atmos. Chem. Phys., 12, 3601-3610, https://doi.org/10.5194/acp-12-3601-2012.

Lucas-Picher, P., J. Cattiaux, A. Bougie, and R. Laprise, 2016: How does large-scale nudging in a regional climate model contribute to improving the simulation of weather regimes and seasonal extremes over North America? Climate Dyn., 46, 929-948, https://doi.org/10.1007/s00382-015-2623-0.

Niu, X. R., and Coauthors, 2018: Ensemble evaluation and projection of climate extremes in China using RMIP models. Int. J. Climatol., 38, 2039-2055, https://doi.org/10.1002/joc.5315.

NOAA, 2011: NOAA CPC Morphing Technique (CMORPH) Global Precipitation Analyses (updated daily). National Center for Atmospheric Research Computational and Information Systems Laboratory Research Data Archive, accessed 16 August 2017, https://doi.org/10.5065/D6CZ356W.

Oh, S. G., J. H. Park, S. H. Lee, and M. S. Suh, 2014: Assessment of the RegCM4 over East Asia and future precipitation change adapted to the RCP scenarios. J. Geophys. Res., 119 , 2913-2927, https://doi.org/10.1002/2013JD020693.

Omrani, H., P. Drobinski, and T. Dubos, 2013: Optimal nudging strategies in regional climate modelling: Investigation in a BigBrother experiment over the European and Mediterranean regions. Climate Dyn., 41, 2451-2470, https://doi.org/10.1007/ s00382-012-1615-6.

- - , and,- 2015 : Using nudging to improve globalregional dynamic consistency in limited-area climate modeling: What should we nudge? Climate Dyn., 44, 1627-1644, https://doi.org/10.1007/s00382-014-2453-5.

Park, J. H., S. G. Oh, and M. S. Suh, 2013: Impacts of boundary conditions on the precipitation simulation of RegCM4 in the CORDEX East Asia domain. J. Geophys. Res. Atmos., 118, 1652-1667, https://doi.org/10.1002/jgrd.50159.

Radu, R., M. Deque, and S. Somot, 2008: Spectral nudging in a spectral regional climate model. Tellus, 60A, 898-910, https:// doi.org/10.1111/j.1600-0870.2008.00341.x.

Ramzan, M., S. Ham, M. Amjad, E. C. Chang, and K. Yoshimura, 2017: Sensitivity evaluation of spectral nudging schemes in historical dynamical downscaling for South Asia. $A d v$. Meteor., 2017, 7560818, https://doi.org/10.1155/2017/7560818.

Rockel, B., 2015: The regional downscaling approach: a brief history and recent advances. Curr. Climate Change Rep., 1, 22-29, https://doi.org/10.1007/s40641-014-0001-3.

Salameh, T., P. Drobinski, and T. Dubos, 2010: The effect of indiscriminate nudging time on large and small scales in regional climate modelling: Application to the Mediterranean basin. Quart. J. Roy. Meteor. Soc., 136, 170-182, https://doi.org/ 10.1002/qj.518.

Shan, H., Y. Guan, and J. Huang, 2012: Effects of spectral nudging on the 2010 East Asia summer monsoon using WRF Model. Chin. J. Oceanol. Limnol., 30, 1105-1115, https://doi.org/ 10.1007/s00343-012-1272-y.

Skamarock, W. C., 2004: Evaluating mesoscale NWP models using kinetic energy spectra. Mon. Wea. Rev., 132, 3019-3032, https://doi.org/10.1175/MWR2830.1. 
, and Coauthors, 2008: A description of the Advanced Research WRF version 3. NCAR Tech. Note NCAR/TN-475+STR, 113 pp., https://doi.org/10.5065/D68S4MVH.

Spero, T. L., M. J. Otte, J. H. Bowden, and C. G. Nolte, 2014: Improving the representation of clouds, radiation, and precipitation using spectral nudging in the Weather Research and Forecasting model. J. Geophys. Res. Atmos., 119, 11 682-11 694 , https://doi.org/10.1002/2014JD022173.

Stauffer, D. R., and N. L. Seaman, 1994: Multiscale 4-dimensional data assimilation. J. Appl. Meteor., 33, 416-434, https://doi.org/ 10.1175/1520-0450(1994)033<0416:MFDDA > 2.0.CO;2.

Tang, J. P., S. Song, and J. A. Wu, 2010: Impacts of the spectral nudging technique on simulation of the East Asian summer monsoon. Theor. Appl. Climatol., 101, 41-51, https://doi.org/ 10.1007/s00704-009-0202-1.

_- , S. Y. Wang, X. R. Niu, P. H. Hui, P. S. Zong, and X. Y. Wang, 2017: Impact of spectral nudging on regional climate simulation over CORDEX East Asia using WRF. Climate Dyn., 48, 2339-2357, https://doi.org/10.1007/ s00382-016-3208-2.

Tiwari, P. R., S. C. Kar, U. C. Mohanty, S. Kumari, P. Sinha, A. Nair, and S. Dey, 2014: Skill of precipitation prediction with GCMs over north India during winter season. Int. J. Climatol., 34, 3440-3455, https://doi.org/10.1002/ joc.3921.

Vincent, C. L., and A. N. Hahmann, 2015: The impact of grid and spectral nudging on the variance of the near-surface wind speed. J. Appl. Meteor. Climatol., 54, 1021-1038, https:// doi.org/10.1175/JAMC-D-14-0047.1.

von Storch, H., H. Langenberg, and F. Feser, 2000: A spectral nudging technique for dynamical downscaling purposes. Mon. Wea. Rev., 128, 3664-3673, https://doi.org/10.1175/1520-0493(2000) $128<3664$ :ASNTFD $>2.0 . \mathrm{CO} ; 2$.

Yhang, Y. B., and S. Y. Hong, 2011: A study on large-scale nudging effects in regional climate model simulation. Asia-Pac. J. Atmos. Sci., 47, 235-243, https://doi.org/10.1007/s13143-011-0012-0.

Zhang, G. H., Z. C. Li, Y. Song, Y. L. Wu, and X. L. Wang, 2011: Spatial pattern of change trend in rainfall of China and the role of East Asia summer monsoon (in Chinese). Arid Land Geogr., 34, 34-42.

Zhao, D. M., 2013: Performance of Regional Integrated Environment Modeling System (RIEMS) in precipitation simulations over East Asia. Climate Dyn., 40, 1767-1787, https://doi.org/ 10.1007/s00382-012-1660-1.

Zhou, W., J. Tang, X. Wang, S. Wang, X. Niu, and Y. Wang, 2016: Evaluation of regional climate simulations over the CORDEX-EA-II domain using the COSMO-CLM model. Asia-Pac. J. Atmos. Sci., 52, 107-127, https://doi.org/10.1007/ s13143-016-0013-0.

Zou, L., and T. Zhou, 2016: Future summer precipitation changes over CORDEX-East Asia domain downscaled by a regional ocean-atmosphere coupled model: A comparison to the standalone RCM. J. Geophys. Res. Atmos., 121, 2691-2704, https:// doi.org/10.1002/2015JD024519. 